\title{
A RET-ER81-NRG1 Signaling Pathway Drives the Development of Pacinian Corpuscles
}

\author{
Michael S. Fleming, ${ }^{1}$ Jian J. Li, ${ }^{2}$ Daniel Ramos, ${ }^{1}$ Tong Li, ${ }^{3}$ David A. Talmage, ${ }^{4}$ Shin-ichi Abe, ${ }^{5}$ Silvia Arber, ${ }^{6}$ \\ and $\odot$ Wenqin Luo ${ }^{1}$ \\ ${ }^{1}$ Department of Neuroscience and 2Department of Neurology, University of Pennsylvania Perelman School of Medicine, Philadelphia, Pennsylvania 19104, \\ ${ }^{3}$ Department of Pathology, Johns Hopkins University, Baltimore, Maryland 21205, ${ }^{4}$ Department of Neurobiology and Behavior, State University of New \\ York at Stony Brook, Stony Brook, New York 11794, ${ }^{5}$ Department of Biological Sciences, Graduate School of Science and Technology, Kumamoto \\ University, 2-39-1 Kurokami, Chuo-ku, Kumamoto 860-8555, Japan, and 'Biozentrum, Department of Cell Biology, University of Basel, 4056 Basel, \\ Switzerland and Friedrich Miescher Institute, 4058 Basel, Switzerland
}

Axon-Schwann cell interactions are crucial for the development, function, and repair of the peripheral nervous system, but mechanisms underlying communication between axons and nonmyelinating Schwann cells are unclear. Here, we show that ER81 is functionally required in a subset of mouse $\mathrm{RET}^{+}$mechanosensory neurons for formation of Pacinian corpuscles, which are composed of a single myelinated axon and multiple layers of nonmyelinating Schwann cells, and Ret is required for the maintenance of Er81 expression. Interestingly, Er81 mutants have normal myelination but exhibit deficient interactions between axons and corpuscle-forming nonmyelinating Schwann cells. Finally, ablating Neuregulin-1 (Nrg1) in mechanosensory neurons results in no Pacinian corpuscles, and an Nrg1 isoform not required for communication with myelinating Schwann cells is specifically decreased in Er81-null somatosensory neurons. Collectively, our results suggest that a RET-ER81-NRG1 signaling pathway promotes axon communication with nonmyelinating Schwann cells, and that neurons use distinct mechanisms to interact with different types of Schwann cells.

Key words: development; ER81; neuregulin 1; neuron Schwann cell interaction; Pacinian corpuscle; RET signaling

\section{Significance Statement}

Communication between neurons and Schwann cells is critical for development, normal function, and regeneration of the peripheral nervous system. Despite many studies about axonal communication with myelinating Schwann cells, mostly via a specific isoform of Neuregulin1, the molecular nature of axonal communication with nonmyelinating Schwann cells is poorly understood. Here, we described a RET-ER81-Neuregulin1 signaling pathway in neurons innervating Pacinian corpuscle somatosensory end organs, which is essential for communication between the innervating axon and the end organ nonmyelinating Schwann cells. We also showed that this signaling pathway uses isoforms of Neuregulin1 that are not involved in myelination, providing evidence that neurons use different isoforms of Neuregulin1 to interact with different types of Schwann cells.

\section{Introduction}

The peripheral nervous system (PNS) contains neurons and two broad classes of Schwann cells: myelinating and nonmyelinating

\footnotetext{
Received July 6, 2016; revised Aug. 19, 2016; accepted Aug. 22, 2016

Author contributions: M.S.F. and W.L. designed research; M.S.F., J.J.L., D.R., and W.L. performed research; T.L., D.A.T., S.-i.A., and S.A. contributed unpublished reagents/analytictools; M.S.F., D.R., and W.L. analyzed data; M.S.F., S.A., and W.L. wrote the paper.

This work was supported by National Institutes of Health Grants R01NS083702 and R01NS094224 to W.L. and Grants F31NS086168, T32HD007516, and T32GM07517 to M.S.F., and the Klingenstein-Simons Fellowship Awards in the Neurosciences to W.L. We thank members of the W.L. laboratory; Drs. Steven Scherer and Brian Pierchala for helpful comments on the manuscript; and the Penn Electron Microscopy Research Laboratory for help taking electron microscopy images.

The authors declare no competing financial interests.

Correspondence should be addressed to Dr. Wenqin Luo, 145 Johnson Pavilion, 3610 Hamilton Walk, Philadelphia, PA 19104. E-mail: luow@mail.med.upenn.edu.

DOI:10.1523/JNEUROSCI.2160-16.2016

Copyright $\odot 2016$ the authors $\quad 0270-6474 / 16 / 3610337-19 \$ 15.00 / 0$
}

Schwann cells. Myelinating Schwann cells produce the myelin sheath insulating large-diameter axons, whereas nonmyelinating Schwann cells help to form specialized sensory and motor endings and bundle small-diameter unmyelinated sensory neurons (Griffin and Thompson, 2008; Monk et al., 2015). Neurons and Schwann cells interact closely to build the PNS, maintain its normal function, and regenerate the PNS when necessary (Jessen et al., 2015; Salzer, 2015; Taveggia, 2016). Despite extensive investigation of myelinating Schwann cells, relatively little is known about communication between axons and nonmyelinating Schwann cells at present.

To gain a better understanding of axonal communication with nonmyelinating Schwann cells, we investigated the development of Pacinian corpuscles in mice. Pacinian corpuscles are large mechanosensory end organs, which sense high-frequency vibration and are classified as rapidly adapting (RA) mechanore- 


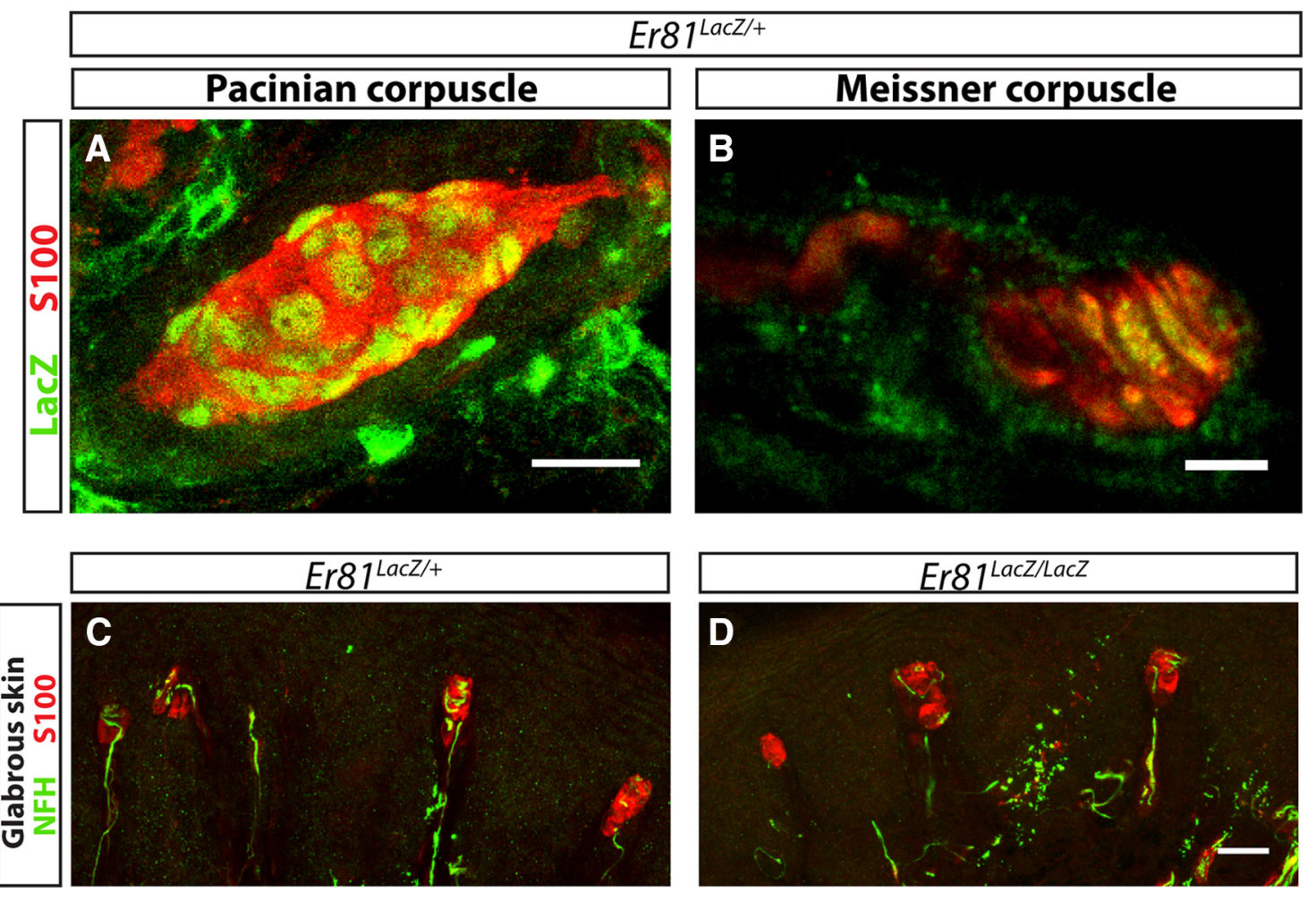

Figure 1. Er81 is expressed in nonmyelinating Schwann cells of Pacinian and Meissner corpuscles. A, Nuclear LacZ driven from the Er81 locus labels the nuclei of Er81 ${ }^{+}$cells. Anti-LacZ (green) immunostaining combined with anti-S100 (red) staining shows Er81 expression in the inner core Schwann cells of Pacinian corpuscles in whole-mount staining of the interosseous membrane at P7. B, Anti-LacZ and anti-S100 immunostaining of hindpaw glabrous skin sections from P21 Er81 lacZ/+ mice shows expression of Er81 in the Schwann cells of Meissner corpuscle end organs.

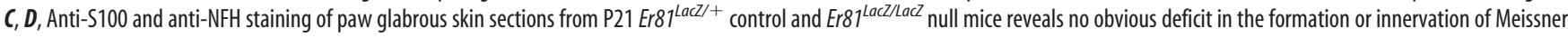
corpuscles in Er81-nulls relative to controls. $N=3$ animals per genotype. Scale bars: $A, C, D, 20 \mu \mathrm{m} ; \boldsymbol{B}, 5 \mu \mathrm{m}$.

ceptors based on their response to sustained stimuli (Zelená, 1994; Fleming and Luo, 2013). Each Pacinian corpuscle is innervated by a single myelinated RA mechanosensory axon. Upon entering the corpuscle, the axon loses its contact with myelinating Schwann cells and directly contacts the corpuscle inner core nonmyelinating Schwann cells (Pease and Quilliam, 1957). Therefore, Pacinian corpuscles present an ideal system to investigate axonal interactions with both myelinating and nonmyelinating Schwann cells.

RA mechanoreceptor innervating neurons develop from DRG neurons, which express the receptor tyrosine kinase Ret during early embryonic development (Bourane et al., 2009; Luo et al., 2009; Honma et al., 2010). In Ret mutant mice, Pacinian corpuscles do not form, whereas the other RA mechanoreceptor endings, such as Meissner corpuscles and lanceolate endings, are still present (Luo et al., 2009). Pacinian corpuscles are also absent in mice lacking the ETS transcription factor Er81 (or Etv1) (Sedý et al., 2006), which controls the central projections and end organ development of proprioceptors in the PNS (Arber et al., 2000; Patel et al., 2003; de Nooij et al., 2013). Because Er81 is expressed in corpuscle-forming Schwann cells, the loss-of-Pacinian corpuscle phenotype was previously attributed to the loss of Er81 function in Schwann cells (Sedý et al., 2006). However, ER81 is also expressed in nonproprioceptive DRG neurons (Arber et al., 2000), raising the possibility that Er81 may be expressed and function in Pacinian corpuscle-innervating neurons.

Neuregulin-1 (NRG1) is one major effector of axon-Schwann cell communication in the PNS (Birchmeier and Nave, 2008). Isoforms of $\mathrm{Nrg} 1$ containing a cysteine-rich domain ( $\mathrm{Nrg1-CRD)}$ are crucial for axonal interactions with myelinating Schwann cells (Michailov et al., 2004). In contrast, Nrg1 isoforms with Ig-like domains (Nrg1-Ig) are required in neurons for the formation of proprioceptive muscle spindles (Hippenmeyer et al., 2002; Cheret et al., 2013). Given that Pacinian corpuscleinnervating axons are highly myelinated and that their end organs are formed by axons and nonmyelinating Schwann cells, it is possible that NRG1 may have unknown important roles in $\mathrm{Pa}$ cinian corpuscle development.

Here, we show that Er81 is expressed in limb RA mechanoreceptor neurons and required in neurons for Pacinian corpuscle development. The maintenance of Er81 expression depends on Ret, but not vice versa. Interestingly, Er81 is likely required for communication between axons and nonmyelinating Schwann cells of Pacinian corpuscles but dispensable for myelination. Finally, we generated mechanosensory neuron-specific mutants of Nrgl and found that Pacinian corpuscles are not formed in these mutant mice. Because the expression of Nrg1-Ig, but not Nrg1$C R D$, is decreased in Er81 mutant mice, ER81 may regulate interactions between axons and nonmyelinating Schwann cells via NRG1-Ig. Collectively, our study establishes a RET-ER81-NRG1 pathway in RA mechanoreceptors for specifying Pacinian corpuscles during development and identifies ER81 as a potential transcriptional regulator of $\mathrm{Nrg1}$. Our results also suggest that neurons use different isoforms of NRG1 to interact with different types of Schwann cells.

\section{Materials and Methods}

Mouse strains. All mice, except for surgical animals, Bace1, and Nrg1-CRD mice, were raised in a barrier facility in Hill Pavilion at the University of 

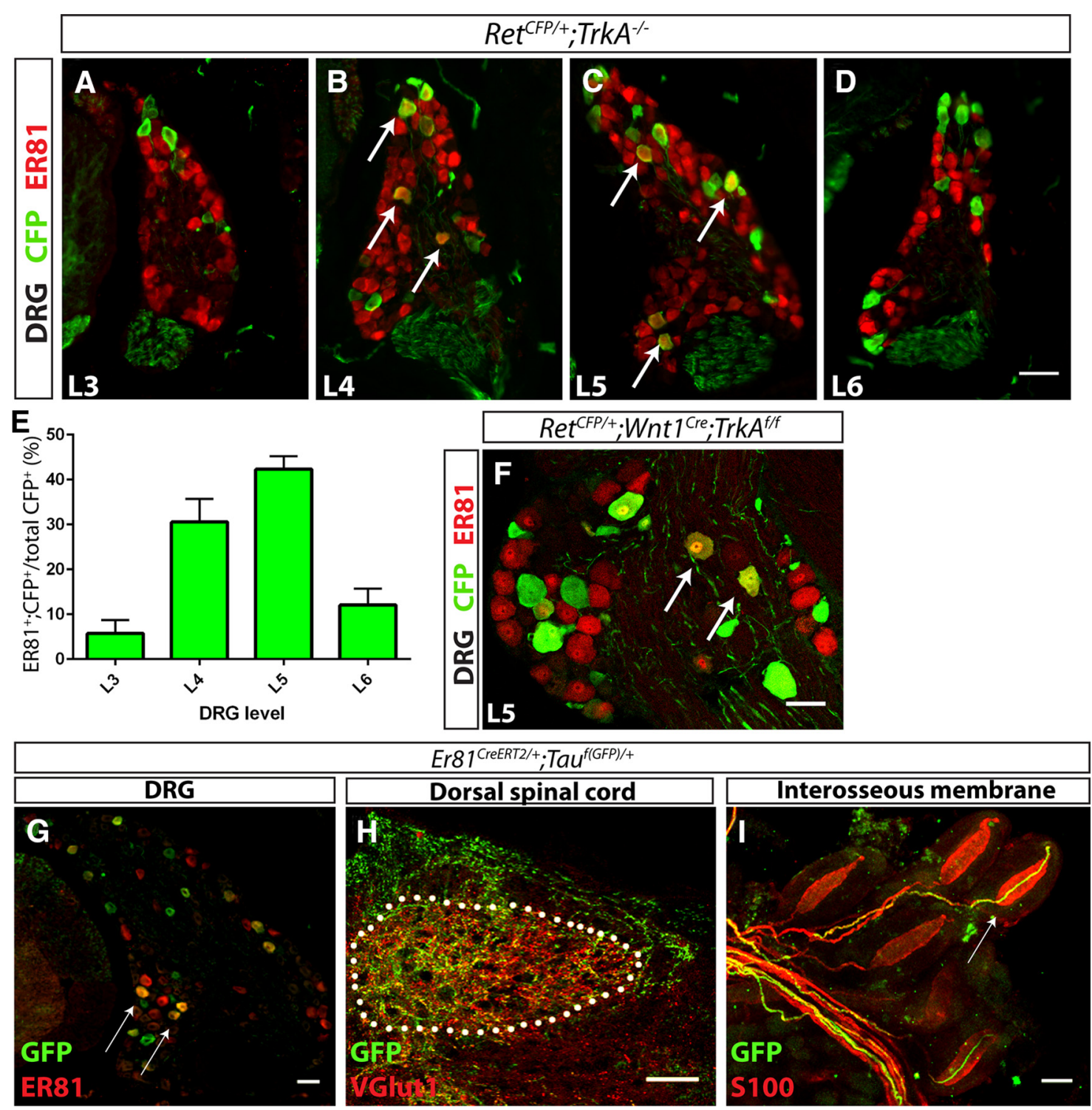

Figure 2. ER81 is expressed in Pacinian corpuscle-innervating neurons. A-E, Anti-CFP (green) and anti-ER81 (red) immunostaining of distal hindlimb-innervating (L4 and L5) and neighboring (L3 and L6) DRG sections of PO Ret ${ }^{\mathrm{CFP} /+} ;{ }^{\prime} T_{k K A^{-1-}}$ mice. A high degree of ER81 expression is present in distal limb-innervating RA mechanoreceptors relative to nondistal limb-innervating RA mechanoreceptors $\left(5.71 \pm 2.43 \%\right.$ of $L 3,30.57 \pm 4.19 \%$ of $L 4,42.30 \pm 2.37 \%$ of $L 5$, and $12.08 \pm 2.98 \%$ of $L 6$ RA mechanoreceptors express ER81). $F, A t P 15,13.5 \pm 1.3 \%$ of CFP ${ }^{+}$RA

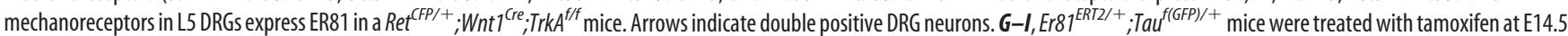
and E15.5, permanently labeling a subset of Er81 ${ }^{+}$cells with GFP, and analyzed at P15. G, Anti-GFP (green) and anti-ER81 (red) immunostaining of DRG sections shows that a subset of ER81 ${ }^{+}$ neurons express GFP. $\boldsymbol{H}$, Dorsal spinal cord immunostaining with anti-VGLUT1 (red), which labels presynaptic terminals of mechanosensory neurons, reveals that GFP ${ }^{+}$neurons innervate mechanosensory-specific layers III-V of the dorsal spinal cord. I, Whole-mount anti-S100 (red) and anti-GFP staining of interosseous membrane shows Pacinian corpuscles innervated by GFP ${ }^{+}$ fibers, as indicated by a white arrow. $N=3$ animals per genotype. Scale bar, $50 \mu \mathrm{m}$. Error bars indicate SEM.

Pennsylvania. Surgical animals were maintained in a conventional facility in John Morgan Building at the University of Pennsylvania. Bace1 mice were raised at the Johns Hopkins mouse facility, and $\mathrm{Nrg1-CRD}$ mice were raised at the mouse facility of the State University of New York at Stony Brook. All mice, except Bace1 and Nrg1-CRD strains, were maintained on a mixed c57 bl/6j and CD1 background. Bace1 and Nrg1-CRD mice were maintained on a c57 bl/6j background. All procedures were conducted according to animal protocols approved by the Institutional Animal Care and Use Committee of the University of Pennsylvania and National Institutes of Health guidelines. Previously described mouse lines include the following: Er81 ${ }^{\text {LacZ }}$ (Arber et al., 2000) (RRID:MGI: 2384496), Wnt1 ${ }^{\text {Cre }}$ (Danielian et al., 1998) (RRID: IMSR_JAX:003829), $\operatorname{Trk} A^{-}$(Fleming et al., 2015), $\operatorname{Trk} A^{f}$ (Chen et al., 2005) (RRID:IMSR_JAX:022362), Ret ${ }^{C F P}$ (Uesaka et al., 2008) (RRID:MGI: 3777556), Er81 ${ }^{\text {CreERT2 }}$ (Taniguchi et al., 2011) (RRID:MGI:4838417), $\mathrm{Tau}^{f(\text { GFP) }}$ (Hippenmeyer et al., 2005) (RRID:MGI:3590682), Nestin ${ }^{\mathrm{Cre}}$ (Tronche et al., 1999) (RRID:MGI:2176173), Er81 ${ }^{f}$ (Patel et al., 2003)
(RRID:MGI:2663693), ROSA-tdTomato (Madisen et al., 2010) (RRID:MGI: 3809523), Dhh ${ }^{\mathrm{Cre}}$ (Jaegle et al., 2003) (RRID:MGI:4359600), Bax- (Knud-

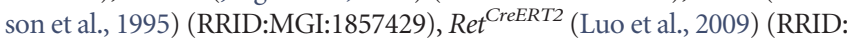
MGI:4437245), $\mathrm{Nrgl}^{f}$ (Zhang et al., 2011) (RRID:MGI:5292107), Nrg1$C_{R D^{-}}$(Wolpowitz et al., 2000) (RRID:MGI:1928831), and Bace1 ${ }^{-}$ (Savonenko et al., 2008) (RRID:MGI:2389228). The $\mathrm{Nrgl}^{-}$allele was generated by crossing an $\mathrm{Nrg}^{\mathrm{fl+}}$ male to a Sox2 $2^{\mathrm{Cre}}$ female (RRID:IMSR_JAX:008454).

Tissue preparation, histology, and in situ hybridization. For immunostaining of spinal columns and DRGs, mice were anesthetized with a mixture of ketamine, xylazine, and acerpromazine by intraperitoneal injection. Mice were then transcardially perfused with PBS, followed by perfusion with 4\% PFA in PBS. Spinal columns were then dissected and postfixed in $4 \%$ PFA in PBS for $2-4 \mathrm{~h}$ at $4^{\circ} \mathrm{C}$, followed by overnight cryoprotection in $30 \%$ sucrose in PBS at $4^{\circ} \mathrm{C}$. In mice processed only for leg and skin tissue for cryosectioning, mice were killed with $\mathrm{CO}_{2}$ followed by cervical 

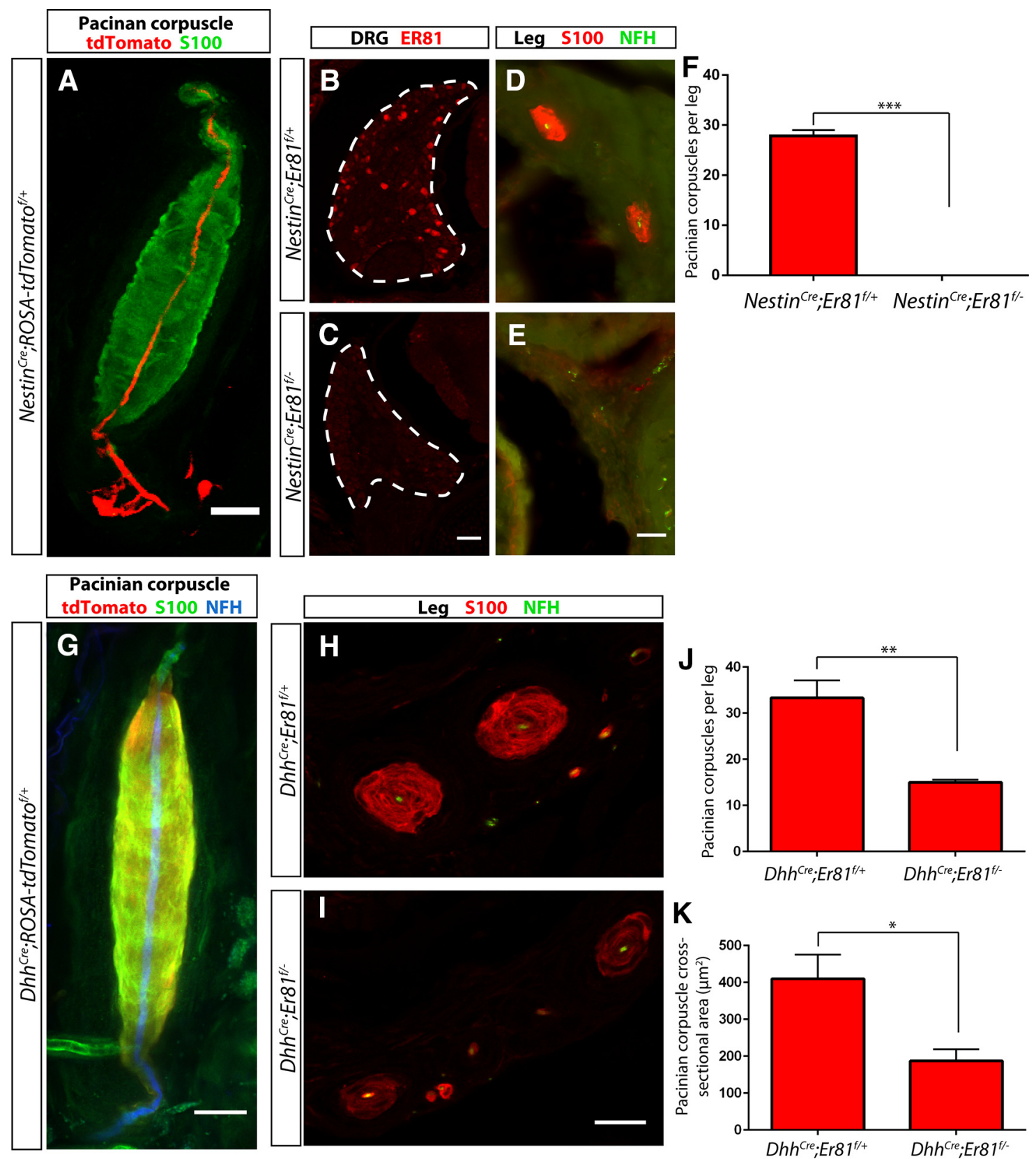

Figure 3. Er81 is absolutely required in neurons, but not Schwann cells, for Pacinian corpuscle development. $A$, Nestin ${ }^{\text {Cre }}$ crossed to a ROSA-tdTomato (red) reporter allele exhibits recombination in innervating fibers but not in the $\mathrm{S}_{100^{+}}$(green) Schwann cells of the Pacinian corpuscle end organ. $\boldsymbol{B}, \boldsymbol{C}$, Anti-ER81 immunostaining of DRG sections from P7 Nestin ${ }^{\mathrm{Cre}}$;Er87 ${ }^{f /+}$ control (B) and $\mathrm{Nestin}^{\mathrm{Cre}} ;$ Err8 $7^{\mathrm{f} /-}$ conditional mutant ( $(\boldsymbol{C})$ shows ablation of ER81 expression in neurons in the mutant mice. $\boldsymbol{D}-\boldsymbol{F}$, Anti-S100 staining of hindlimb sections from P7 control (D) and conditional mutant

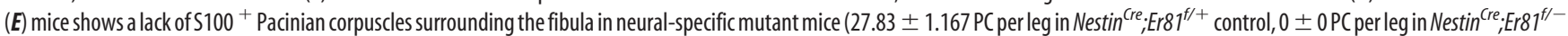
conditional mutant; $p<0.0001)$. G, Dhh ${ }^{\text {Cre }}$ crossed to a ROSA-tdTomato (red) reporter allele reveals reporter activity in $\mathrm{S}_{100^{+}}$(green) inner core Schwann cells of the Pacinian corpuscles, but not

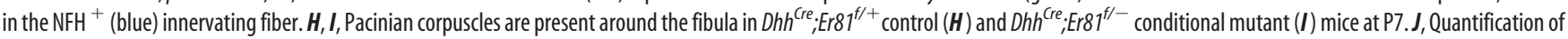
serial leg sections reveals a significant decrease in the number of Pacinian corpuscles per leg in Schwann cell-specific Er81 mutants compared with controls ( $33.33 \pm 3.756 \mathrm{PC}$ per leg in

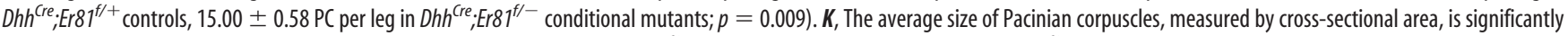
reduced in Schwann cell-specific Er81 mutants (410.1 $\pm 65.3 \mu \mathrm{m}^{2}$ in Dhh ${ }^{\text {Cre }}$;Er8 ${ }^{f /+}$ controls, $187.9 \pm 30.9 \mu \mathrm{m}^{2}$ in Dhh ${ }^{\text {Cre }}$;Err8 $7^{f /-}$ conditional mutants; $\left.p=0.037\right) . N=3$ animals, 6 legs per genotype. Scale bars: $\boldsymbol{A}, \boldsymbol{D}-\mathbf{I}, 20 \mu \mathrm{m} ; \boldsymbol{B}, \boldsymbol{C}, 50 \mu \mathrm{m} .{ }^{*} p<0.05 .{ }^{* *} p<0.01 .{ }^{* * *} p<0.001$. Error bars indicate SEM.

dislocation/decapitation. Paw skin was fixed overnight in 4\% PFA in PBS at $4^{\circ} \mathrm{C}$, followed by cryopreservation. Legs were fixed $2-4 \mathrm{~h}$ in $4 \%$ PFA in PBS at $4^{\circ} \mathrm{C}$, and then decalcified overnight in $22 \%$ formic acid and $10 \%$ sodium citrate in $\mathrm{ddH}_{2} \mathrm{O}$ at room temperature (Luo et al., 2009), followed by cryopreservation. Preserved tissue was then embedded in NEG-50 and sectioned at $20 \mu \mathrm{m}$ (spinal columns/DRGs), 30-40 $\mu \mathrm{m}$ (leg/skin tissue for immunostaining), or 10-15 $\mu \mathrm{m}$ (leg tissue for H\&E staining). For spinal columns, care was taken in the embedding and sectioning process to ensure collection of specific lumbar DRG levels. Serial leg sections from ankle to knee were collected to ensure collection of all Pacinian corpuscles. Cryosection immunostaining was performed as previously reported (Fleming et al., 2015).

Whole-mount interosseous membranes were dissected from hindlimbs following above perfusion procedure and then postfixed for 2-4 $\mathrm{h}$ as above. Following fixation, whole-mount membranes were permeabilized $3 \times 10$ min with PBS with 1\% Triton X-100 and 1\% Tween 20 . Antibody incubation was performed overnight at room temperature with rocking in PBS plus 5\% lamb serum, 1\% Triton X-100, and 1\% Tween 20 . The following day, sections were washed $3 \times 1 \mathrm{~h}$ with PBS plus 

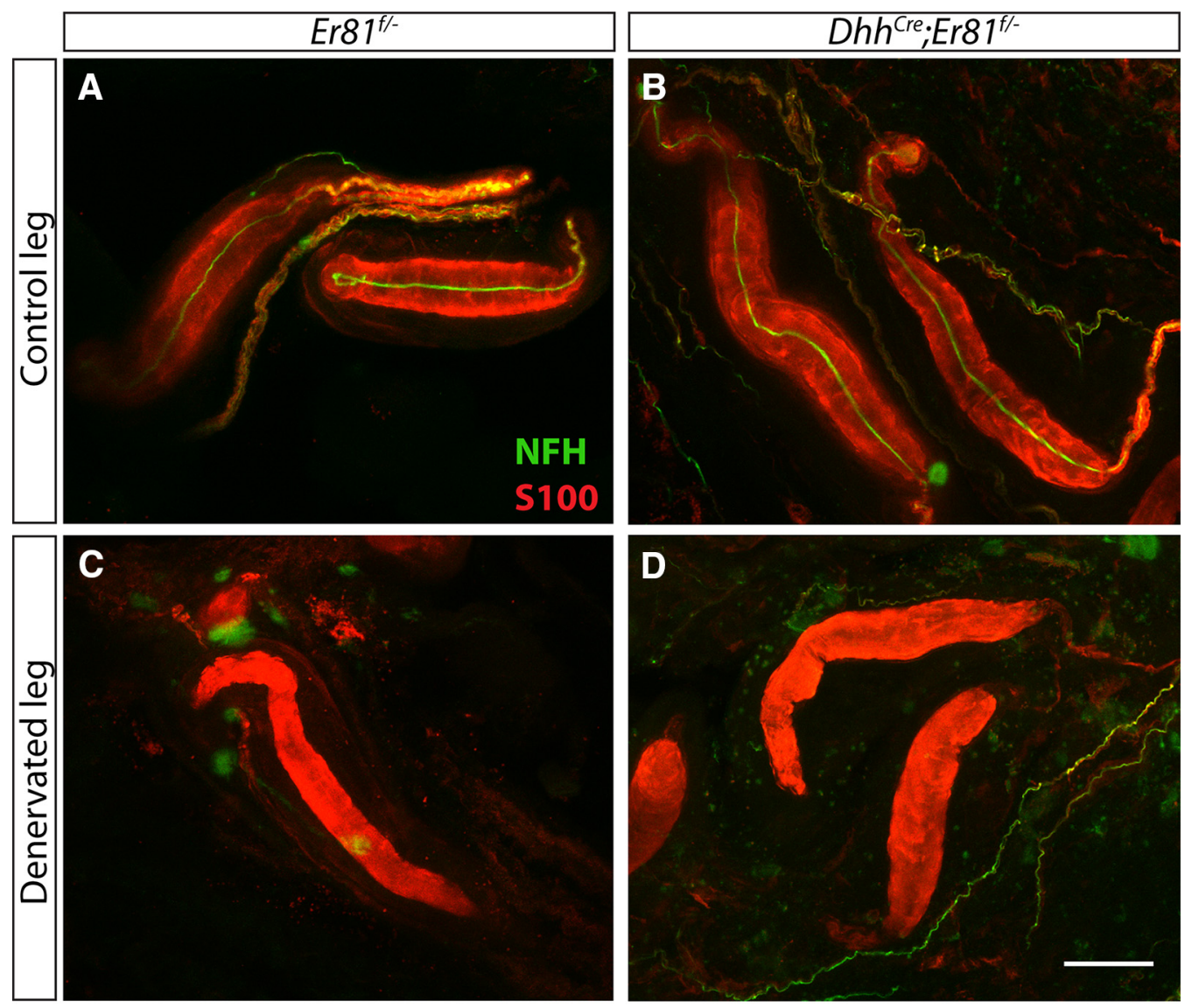

E

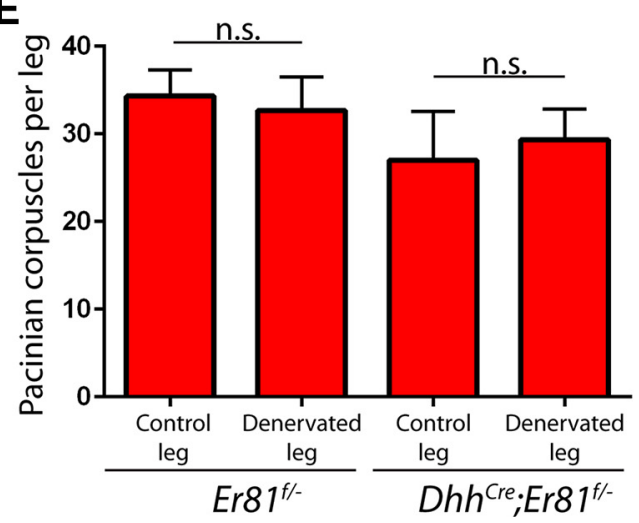

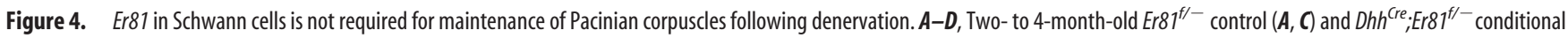
mutants $(\boldsymbol{B}, \boldsymbol{D})$ underwent unilateral tibial nerve transection and recovered for 2 weeks before tissue processing. Denervation was confirmed by the loss of NFH ${ }^{+}$(green) axons innervating $S 100^{+}$ (red) Pacinian corpuscles in whole-mount interosseous membrane staining of the denervated limb $(\boldsymbol{C}, \boldsymbol{D})$, in contrast to $\mathrm{NFH}^{+}$innervation in the nonsurgical limb $(\boldsymbol{A}, \boldsymbol{B})$. $\boldsymbol{E}, \mathbf{Q u a n t i f i c a t i o n ~ o f ~} \mathrm{S} 100^{+}$ Pacinian corpuscles in serial hindlimb sections in Er87 ${ }^{f /-}$ controls (34.33 \pm 2.96 corpuscles per nonsurgical limb, $32.67 \pm 3.84$ corpuscles per denervated limb; $\left.p=0.75\right)$ and Dhh ${ }^{\text {Cre }}$; Er8 $87^{f /-}$ conditional mutants ( $27.00 \pm 5.57$ corpuscles per nonsurgical limb, $29.33 \pm 3.53$ corpuscles per denervated limb; $p=0.74$ ) shows that loss of Er81 in Schwann cell does not cause a deficit in the maintenance of Pacinian corpuscles following denervation. $N=3$ legs per condition. Not significant: $p \geq 0.05$. Error bars indicate SEM. Scale bar, $50 \mu \mathrm{m}$.

$1 \%$ Tween 20. Secondary antibody incubation was performed overnight at room temperature with rocking in PBS plus 5\% lamb serum and $1 \%$ Tween 20. Samples were then washed $3 \times 1 \mathrm{~h}$ in PBS plus $1 \%$ Tween 20, and then cleared in 50\% glycerol in PBS for 30 min, followed by $75 \%$ glycerol in PBS for $30 \mathrm{~min}$, and then mounted and imaged in 75\% glycerol in PBS.

Antibodies used were as follows: chicken anti-LacZ (1:500, Aves Laboratories catalog \#BGL-1040 RRID:AB_2313507), chicken anti-GFP (1:500, Aves Laboratories catalog \#GFP-1020 RRID:AB_10000240), chicken anti-neurofilament heavy-chain (NFH) (1:500, Aves Laboratories catalog \#NF-H RRID:AB_2313552), guinea pig anti-VGLUT1 (1: 1000, Millipore catalog \#AB5905 RRID:AB_2301751), rabbit anti-S100
(1:400, Dako catalog \#Z031129-2 RRID:AB_2315306), rabbit anti-ER81 (1:1000) (Arber et al., 2000) (RRID:AB_2617167), and AlexaFluorconjugated goat or donkey raised secondary antibodies (1:500, Invitrogen or Jackson ImmunoResearch Laboratories). H\&E staining was performed as previously described (Luo et al., 2009). In situ hybridization was performed as previously described (Fleming et al., 2015).

For electron microscopy studies, anesthetized mice were transcardially perfusion fixed with $2 \%$ PFA and $2 \%$ glutaraldehyde in $0.1 \mathrm{~m}$ phosphate buffer, $\mathrm{pH}$ 7.4. The tissues were quickly removed, then postfixed in perfusing solution for at least $4 \mathrm{~h}$ at $4^{\circ} \mathrm{C}$. Nerves were osmicated and dehydrated. They were treated twice with propylene oxide for $5 \mathrm{~min}$, incubated sequentially with Embed 812:propylene oxide mixtures (1:1 

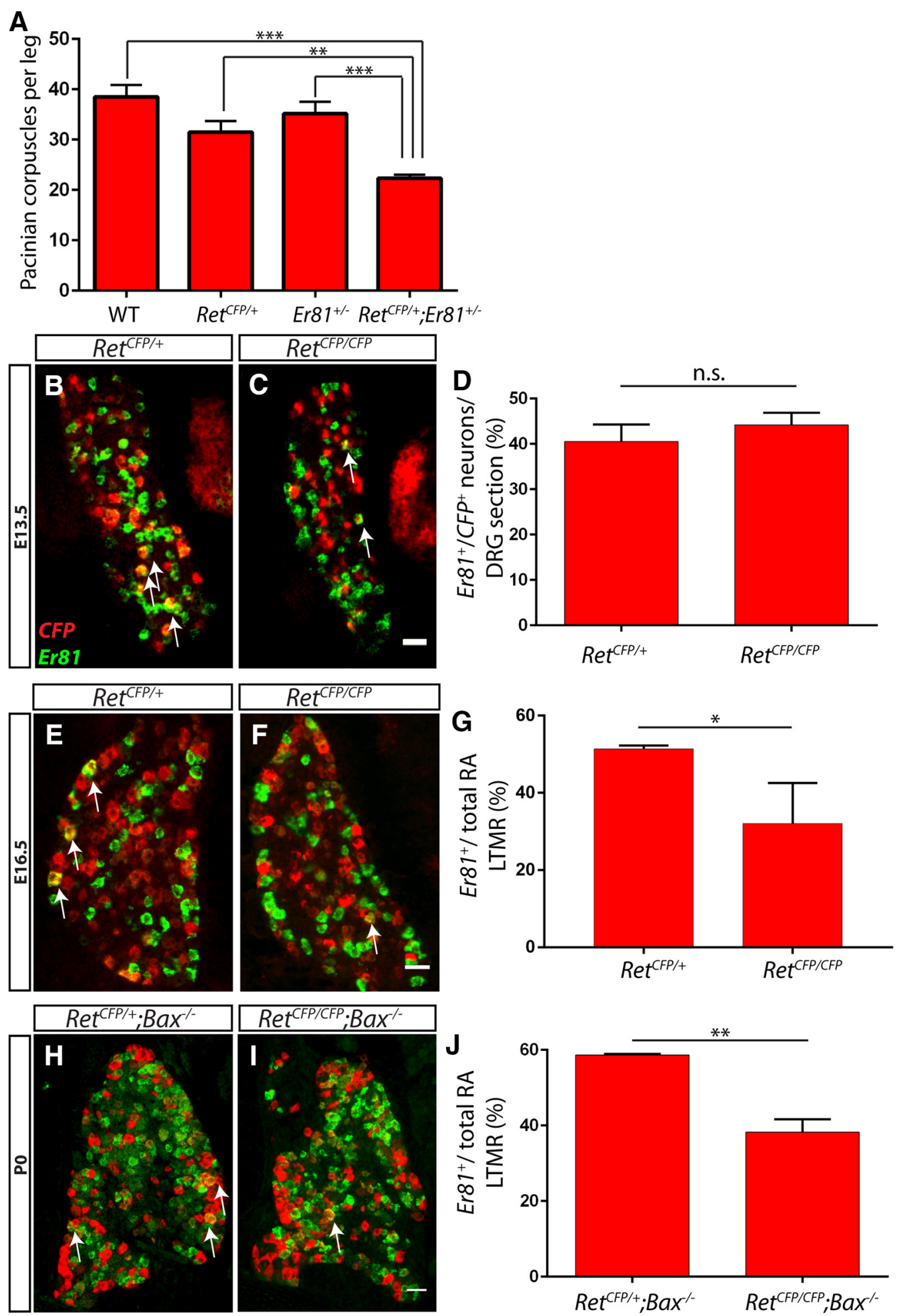

Figure 5. Ret is required for the maintenance, but not initiation, of Er87 expression in RA mechanoreceptors. $A$, The number of $S 100^{+}$Pacinian corpuscles per limb was quantified in serial sections of P14-P21 wild-type $\left(38.50 \pm 2.36\right.$ Pacinian corpuscles per limb), Ret ${ }^{C F P /+}\left(31.50 \pm 2.23\right.$ Pacinian corpuscles per limb), Er81 ${ }^{+/-}$( $35.17 \pm 2.40$ Pacinian corpuscles per limb), and Ret ${ }^{C F P /+}$; $\mathrm{Er} 81^{+/-}\left(22.33 \pm 0.71\right.$ Pacinian corpuscles per limb) hindlimbs. The number of Pacinian corpuscles in Ret ${ }^{\mathrm{CPP} /+} ; \mathrm{Err8}^{+/-}$double heterozygotes is significantly less than in all other genotypes. $\boldsymbol{B}-\boldsymbol{D}$, Double-fluorescent in situ hybridization against CFP (red) driven from the Ret locus and Er81 (green) in L4/L5 DRGs of Ret ${ }^{C F /+}$ and Ret ${ }^{C F P / C F}$ embryos at E13.5. The percentage of $C F P^{+}$neurons expressing Er81 is similar between controls and mutants (40.55 $\pm 3.74 \%$ in Ret ${ }^{C F /+}$ DRGs, $44.19 \pm 2.65 \%$ in Ret ${ }^{C F /(C F P}$ DRGs; $\left.p=0.47\right)$. E-G, At E16.5, CFP/Er81 double-fluorescent in situ hybridization shows a decrease in the proportion of RA mechanoreceptors that express Er87in Ret mutants relative to controls $\left(51.40 \pm 0.50 \%\right.$ in Ret ${ }^{C F P /+}$ DRGs, 32.12 $\pm 6.03 \%$ in Ret ${ }^{C F P / C F P}$ DRGs; $p=0.03) \cdot \boldsymbol{H}-\boldsymbol{J}$, (FP/Er81 double-fluorescent in situ hybridization of PO Ret mutants and controls in an apoptosis-deficient Bax-null background shows a significant decrease in the percentage of RA

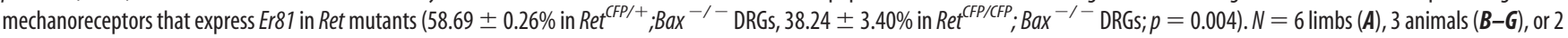
animals $(\boldsymbol{H}-\boldsymbol{J})$ per genotype. Scale bar, $50 \mu \mathrm{m} .{ }^{*} p<0.05 .{ }^{* *} p<0.01 .{ }^{* * *} p<0.001$. Not significant, $p>0.05$. Error bars indicate SEM. 


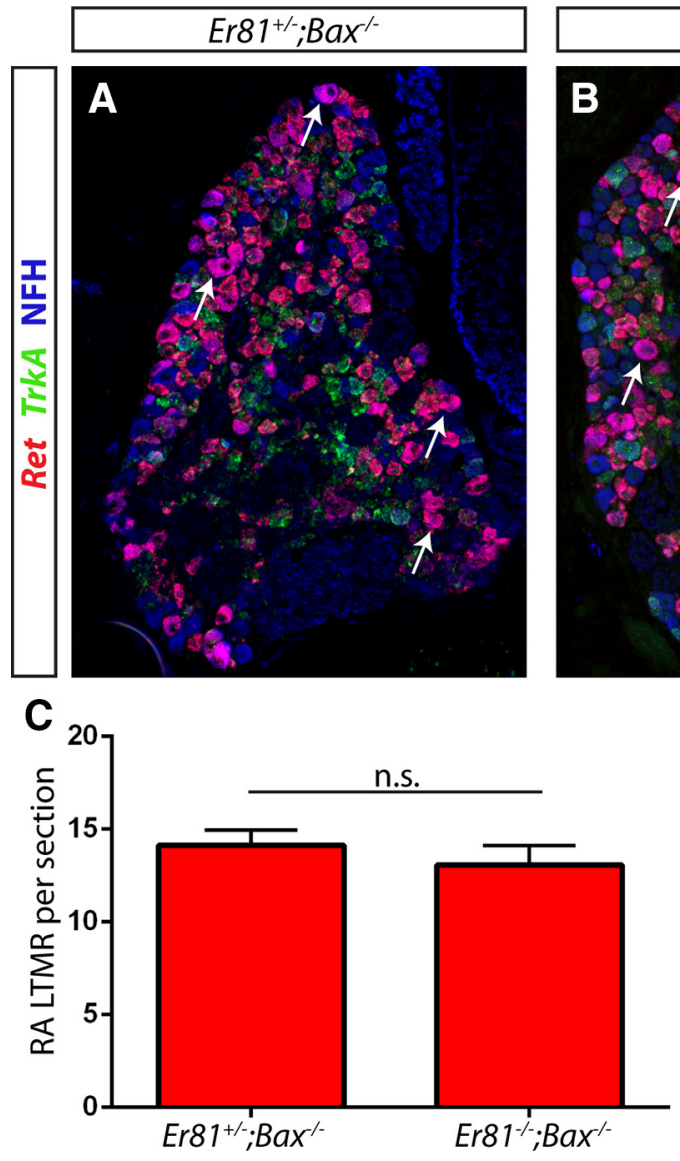

Figure 6. Er81 does not affect the expression of Ret in RA mechanoreceptors. $\boldsymbol{A}-\boldsymbol{C}$, The number of $\operatorname{Ret}^{+} ; \mathrm{TrkA}^{-} ; \mathrm{NFH}^{+} \mathrm{RA}^{-}$ mechanoreceptors per L4/L5 DRG section was similar between Er81 mutants and controls in an apoptosis-deficient background at P3-P5, suggesting that Er81 does not regulate the expression of Ret in RA mechanoreceptors (14.12 \pm 0.82 RA mechanoreceptors per section in $\mathrm{Er}_{81^{+/-}} ; \mathrm{Bax}^{-/-}$controls, $13.06 \pm 1.06 \mathrm{RA}$ mechanoreceptors per section in $\mathrm{Er}^{-1} 1^{-/-} ; \mathrm{Bax}^{-/-}$double mutants; $p=0.47)$. Arrows indicate some Ret ${ }^{+} ; \mathrm{TrkA}^{-} ; \mathrm{NFH}^{+}$neurons. $N=3$ animals per condition, $\geq 8$ sections per animal. Not significant: $p \geq 0.05$. Error bars indicate SEM. Scale bar, $100 \mu \mathrm{m}$.

and 2:1), and incubated in pure Embed 812 mixture (Electron Microscopy Sciences) overnight. Tissues were then embedded in fresh Embed 812 mixture at $60^{\circ} \mathrm{C}$ for $48 \mathrm{~h}$. For light microscopy, $1-\mu \mathrm{m}$-thick, transverse sections were stained with alkaline toluidine blue. For electron microscopy, $0.1 \mu \mathrm{m}$ thick, transverse sections were stained with lead citrate.

Image acquisition. Fluorescent images were collected on a Leica SP5II confocal microscope and a Leica DM5000B microscope. Bright-field images were collected with a Leica DM5000B microscope. Electron micrographs were collected on a Jeol-1010 transmission electron microscope.

Animal surgery. Two- to 4-month-old mice were anesthetized with the inhalation of $\sim 3 \%$ isoflurane in an induction chamber and then maintained on $1 \%-2 \%$ isoflurane through a nose cone throughout the procedure. Before making the surgical incision, a very small volume (no $>2$ $\mathrm{mg} / \mathrm{kg}$ ) of bupivacaine $(0.25 \%)$ was injected with a 25 gauge needle at equidistant places $\sim 0.5-1 \mathrm{~cm}$ apart, in an ellipse around the incision site. Following incision, the overlying muscle was dissected and the right tibial nerve was doubly ligated with 5-O silk threads, and transected between the ligations with iridectomy scissors. The proximal and distal ends were separated by a gap and attached to an adjacent muscle with a suture. The skin was then sutured with 5-O silk threads. Following surgery, mouse was given subcutaneous injection of $\sim 1 \mathrm{ml}$ of lactated Ringer's solution to prevent dehydration and was kept on a heating pad until fully recovered from anesthesia. Meloxicam ( $2 \mathrm{mg} / \mathrm{kg}$, s.c.) was given at the time of anesthesia induction and every $12 \mathrm{~h}$ for $2 \mathrm{~d}$ after surgery. Mice were then processed for collection of leg tissue 2 weeks to 3 months following surgery as above.
Tamoxifen treatment. Timed pregnancies were set up in the evening, and female mice were checked for vaginal plug the following morning. The time that vaginal plug was observed was considered embryonic day 0.5 (E0.5). Pregnant dams carrying the Er81 ${ }^{\text {CreERT2 }}$ embryos were treated with $10 \mathrm{mg}$ of tamoxifen dissolved in sunflower oil by oral gavage at E14.5 and E15.5. Pregnant dams carrying the Ret $^{\text {CreERT2 }}$ embryos were treated with $5 \mathrm{mg}$ of tamoxifen, $5 \mu \mathrm{g} \beta$-estradiol, and $2.5 \mathrm{mg}$ progesterone dissolved in sunflower oil by oral gavage at E13.5 and E14.5.

Quantification and statistics. For histological analysis of DRG neurons, at least 6 sections per animal were quantified. Image names were randomized after collection to blind experimenter to genotype of images. Pacinian corpuscle counts were performed by manually scanning slides of anti-S100/anti-NFH-stained serial cryosections. Pacinian corpuscles, that appeared at similar locations in consecutive sections were not double counted. Pacinian corpuscle size measurements were obtained by imaging every fifth serial section, to avoid double counting individual corpuscles, which span multiple sections. The area of individual corpuscle cross sections was then measured by manually tracing the $\mathrm{S} 100^{+}$corpuscle inner cores in ImageJ. G-ratios were calculated by manually measuring the area of individual fibers and their axons in ImageJ, and then calculating the diameter of fibers based on the assumption that the measured areas corresponded to a circle. $p$ values were calculated by unpaired $t$ tests after finding the mean measurement for each individual animal. Statistical analysis was performed with GraphPad Prism software.

\section{Results}

Er81 is required for the development of Pacinian, but not Meissner, corpuscles

Pacinian corpuscles and their innervating axons are absent in Er81 mutant mice around birth (Sedý et al., 2006), but how ER81 contributes to Pacinian corpuscle formation is unclear. The lack of Pacinian corpuscles in Er81 mutants may be due to its function in Schwann cells, as Er81 is expressed in the inner core nonmyelinating Schwann cells of Pacinian corpuscles (Sedý et al., 2006). To test this idea, we examined whether Er81 is specifically expressed in Pacinian corpuscle nonmyelinating Schwann cells or broadly expressed in other end organ Schwann cells of RA mechanoreceptors, such as in Meissner corpuscles (Zelená, 1994; Fleming and Luo, 2013). Using an $E r 81^{\text {LacZ }}$ reporter allele (Arber et al., 2000), we found that Er81 is expressed in Pacinian (Sedý et al., 2006) as well as Meissner corpuscle inner core Schwann cells (Fig. 1A,B), suggesting that Er81 is not specifically expressed in Pacinian corpuscle inner core Schwann cells. Next, we asked whether Er81 is also required for Meissner corpuscle formation during development. We confirmed the complete absence of Pacinian corpuscles in Er81-null mice (Sedý et al., 2006) (data not shown). However, when we examined Meissner corpuscles of postnatal day 21 (P21) control and Er81-null mice, we found that they are normal in the mutant dermal papillae (Fig. $1 C, D$ ). Thus, like Ret, Er81 is required for the development of Pacinian corpuscles but not Meissner corpuscles. This result suggests that Er81 

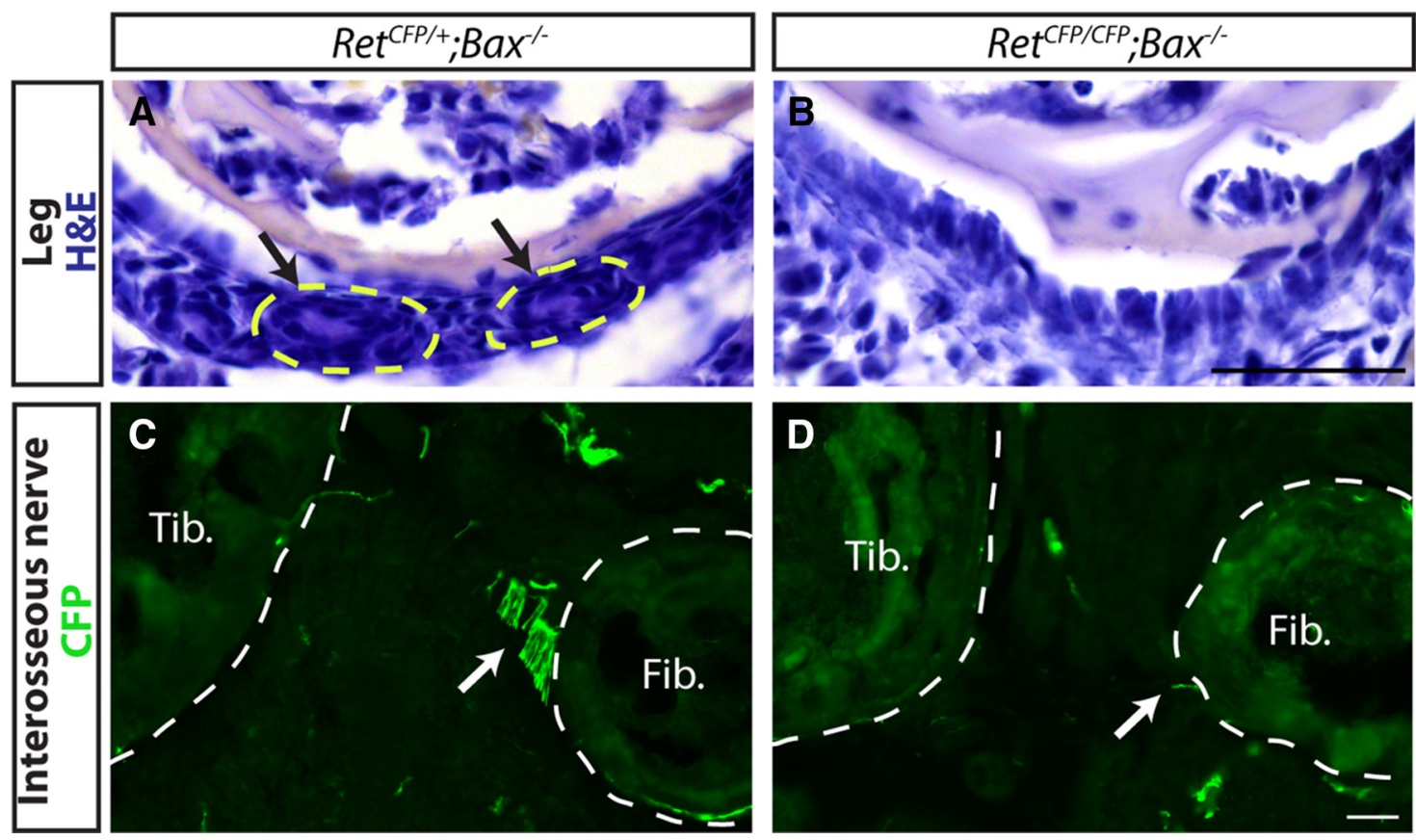

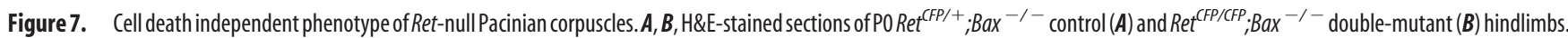

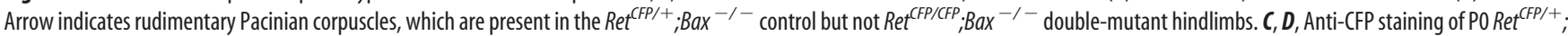
$\mathrm{Bax}^{-1-}$ and Ret ${ }^{C F /(C F P} ; B a x^{-1-}$ hindlimbs, which labels the axons of RA mechanoreceptors. Arrow indicates axons of interosseous nerve, which are absent in double mutants. $\mathrm{T}$, Tibia; $\mathrm{F}$, fibula. $n=$ 2 animals per genotype. Scale bar, $50 \mu \mathrm{m}$.

may act in a cell type other than Schwann cells to promote Pacinian corpuscle end organ formation.

\section{Er81 is expressed in Pacinian corpuscle-innervating neurons} To determine whether ER81 functions in Pacinian corpuscleinnervating neurons, we first asked whether ER81 is expressed in RA mechanoreceptors at distal limb-innervating levels, where Pacinian corpuscle-innervating neurons are mainly found. We quantified the proportion of RA mechanoreceptors that are immunopositive for ER81 in P0 $\mathrm{Ret}^{\mathrm{CFP} /+}$;TrkA ${ }^{-/-}$DRG sections. In this genetic background, all $\operatorname{Ret}^{+}$neurons were identified with anti-GFP immunostaining. Additionally, because all $\operatorname{Ret}^{+}$DRG neurons in addition to RA mechanoreceptors depend on NGF/TrkA signaling for their survival and expression of Ret (Luo et al., 2007; Luo et al., 2009), most $\mathrm{CFP}^{+}$neurons in these sections should be RA mechanoreceptors. Using this strategy, we found that $\sim 40 \%$ of RA mechanoreceptors in distal hindlimbinnervating DRGs (L4 and L5) express ER81, whereas only 10\% of RA mechanoreceptors in surrounding DRGs (L3 and L6) express ER81 (Fig. 2A-E). Therefore, ER81 is enriched in distal hindlimb-innervating RA mechanoreceptors. To determine whether limb RA mechanoreceptors maintain expression of ER81 postnatally, we examined ER81 expression in P15 et $^{\text {CFP/+ }}$; Wnt $1^{\text {Cre }} ; \operatorname{Trk} A^{\text {flf }}$ L5 DRGs. Conditional TrkA mutants were used here instead of constitutive TrkA-nulls because TrkA-null mice die at $\sim \mathrm{P} 0$. We found that $13.5 \pm 1.3 \%$ of $\mathrm{CFP}^{+}$neurons express ER81 at this age (Fig. 2F). The decrease in the proportion of L5 ER81 ${ }^{+}$RA mechanoreceptors from P0 to P15 suggests that ER81 is downregulated during postnatal development.

To directly demonstrate that ER $81^{+}$DRG neurons innervate Pacinian corpuscles, we crossed a tamoxifen-inducible Cre recombinase driven from the Er81 locus to a Tau ${ }^{G F P}$ conditional reporter allele, and treated pregnant dams with tamoxifen at embryonic day 14.5 (E14.5) and E15.5 to permanently label ER81 ${ }^{+}$ neurons with GFP. At P15, tamoxifen-treated mice displayed GFP expression in a subset of ER81 ${ }^{+}$DRG neurons (Fig. 2G). Notably, a few $\mathrm{GFP}^{+}$neurons no longer expressed ER81 at P15, consistent with the idea that some DRG neurons may have downregulated Er81 during development. GFP ${ }^{+}$axons innervated layers III-V of the dorsal spinal cord, the target zone of mechanosensory neurons (Fig. $2 \mathrm{H}$ ). Additionally, whole-mount staining of the interosseous membrane showed that a subset of Pacinian corpuscles is innervated by $\mathrm{GFP}^{+}$axons (Fig. $2 I$ ). The lack of $\mathrm{GFP}^{+}$axons innervating all Pacinian corpuscles is likely due to the incomplete recombination efficiencies of the inducible Cre and reporter allele. Collectively, our results indicate that Er81 is expressed in Pacinian corpuscle-innervating DRG neurons.

Er81 is required in neurons, but not Schwann cells, for Pacinian corpuscle formation during development

To determine in which cell type Er81 is required for Pacinian corpuscle formation during development, we combined an Er81 conditional allele with tissue-specific Cre lines. We generated conditional mutants with Nestin ${ }^{\mathrm{Cre}}$, which drives recombination in Pacinian corpuscle-innervating neurons but not corpuscle Schwann cells (Fig. 3A). Anti-ER81 immunostaining was absent from DRG sections of Nestin ${ }^{\mathrm{Cre}} ; \mathrm{Er}_{81}{ }^{f /-}$ mice, demonstrating efficient recombination of the Er81 $1^{f}$ allele in DRG neurons (Fig. $3 B, C)$. Serial sections of $\mathrm{P} 7$ mutant hindlimbs revealed a complete absence of Pacinian corpuscles around the fibula (Fig. $3 D, E)$. Therefore, Er81 is absolutely required in neurons for $\mathrm{Pa}$ cinian corpuscle formation during development.

Because Er81 is also expressed in the Pacinian corpuscle inner core Schwann cells, we next asked whether Er81 in Schwann cells also contributes to Pacinian corpuscle development. We used a Desert Hedgehog ${ }^{\mathrm{Cre}}\left(\mathrm{Dhh}^{\mathrm{Cre}}\right)$ transgenic line, which drives recombination in Pacinian corpuscle Schwann cells but not their innervating neurons (Fig. $3 F$ ), to ablate Er81. At P7, Dhh ${ }^{\text {Cre }}$; 

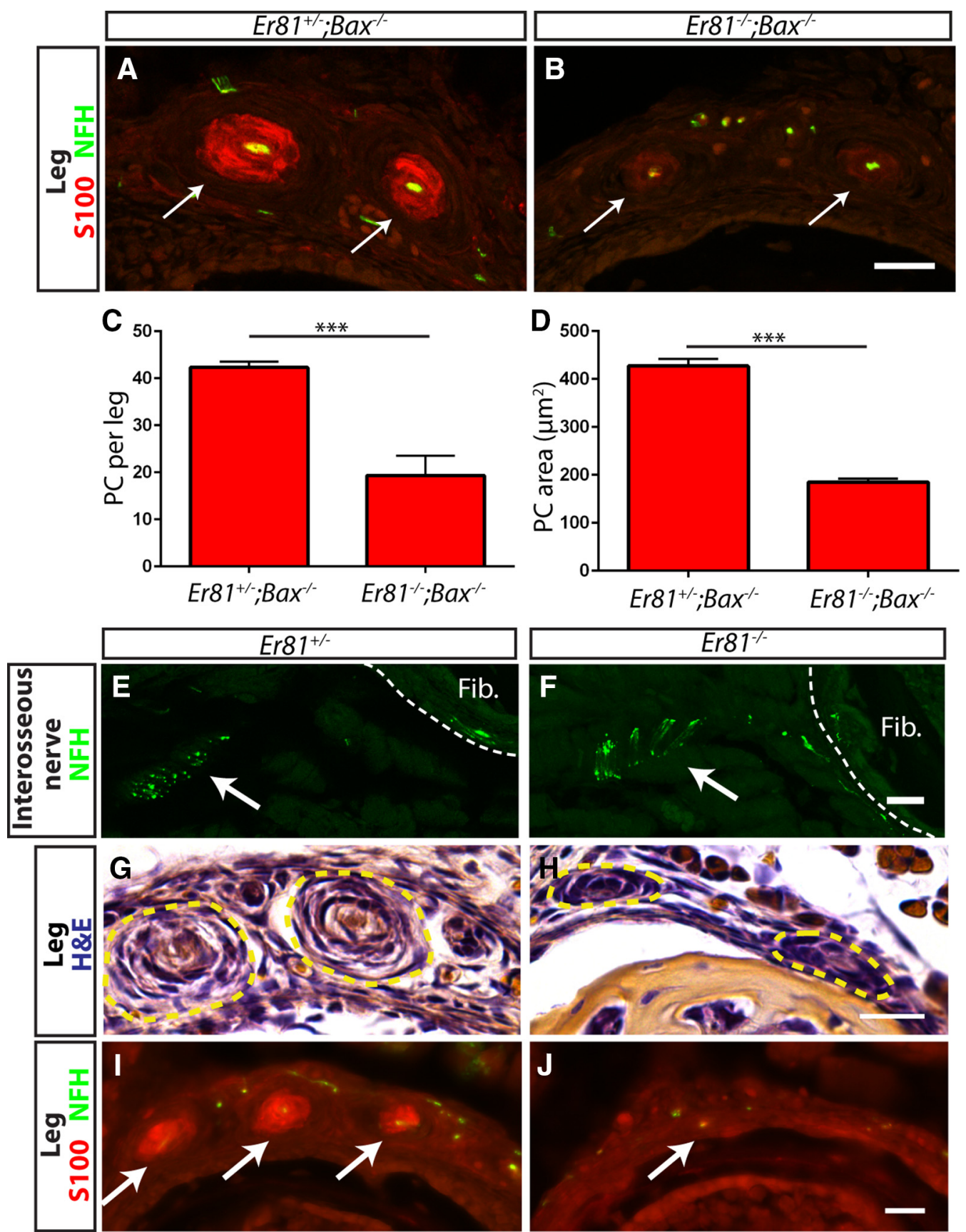

Figure 8. The primary deficit in Pacinian corpuscle formation in Er81 mutants is deficient axon/Schwann cell communication. $\boldsymbol{A}, \boldsymbol{B}$, Anti-S100 (red) and anti-NFH (green) staining of P3

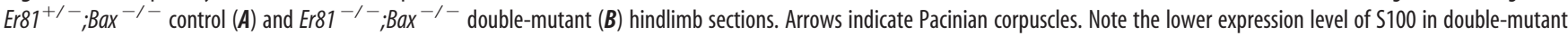
Pacinian corpuscles relative to controls. C, Quantification of $\mathrm{S} 00^{+}$Pacinian corpuscles in serial leg sections reveals a significant decrease in the number of corpuscles formed in double mutants relative to controls ( $42.33 \pm 1.20 \mathrm{PC}$ per leg in Er81 ${ }^{+/-} ; \mathrm{Bax}^{-/-}$controls, $19.33 \pm 4.18 \mathrm{PC}$ per leg in Er81 ${ }^{-/-} ; B a x^{-\prime-}$ double mutants; $\left.p=0.006\right)$. D, Quantification of average cross-sectional area of Pacinian corpuscle inner cores reveals a significant decrease in the size of the remaining Pacinian corpuscles in double mutants $\left(427.3 \pm 14.7 \mu \mathrm{m}^{2}\right.$ in Er8 ${ }^{+/-}$;Bax ${ }^{-/-}$controls, $185.3 \pm$ $6.7 \mu \mathrm{m}^{2}$ in $E r 81^{-\prime-} ; B a x^{-\prime-}$ double mutants; $\left.p=0.0001\right) . E, F$, Anti-NFH staining of P2 interosseous nerve shows intact innervation of fibula/interosseous membrane in both Er81 ${ }^{+/-}$control (E) and $E r 81^{-/-}$mutant $(\boldsymbol{F})$ mice. $\boldsymbol{G}, \boldsymbol{H}, \mathrm{H} \& \mathrm{E}$ staining of P2 hindlimbs shows early Pacinian corpuscles forming in the Er8 $81^{+/-}$control (G). However, Schwann cells form much smaller, rudimentary Pacinian corpuscles in the Er81 ${ }^{-/-}$mutant $(\boldsymbol{H}) . \boldsymbol{I}, \boldsymbol{J}$, Anti-S100 (red) and anti-NFH (green) staining shows that mature Schwann cells are present in corpuscles by P2 in the control $(\boldsymbol{I})$ but are absent in the mutant $(J) . N=3$ animals, 6 legs per genotype. Scale bar, $20 \mu \mathrm{m} .{ }^{* *} p<0.001$. Error bars indicate SEM.

Er81 ${ }^{f /-}$ mutant mice had significantly fewer and smaller Pacinian corpuscles (Fig. 3G-J). Nevertheless, the phenotype in the Schwann cell-specific mutants is much less severe compared with that of neural-specific mutants. Additionally, the Pacinian corpuscle number in adult $D h h^{C r e} ; E r 81^{f /-}$ mutant mice catches up to control levels (Fig. 4E), suggesting that development of Pacinian corpuscles may be delayed when Er81 is ablated from Schwann cells. Thus, Er81 in Schwann cells contributes to, but is less critical for, Pacinian corpuscle formation during development.

Er81 in Schwann cells is not required for Pacinian corpuscle maintenance following injury

Although nerve innervation is absolutely required for the developmental formation of Pacinian corpuscles (Zelená, 1980), Pa- 
cinian corpuscles can survive for up to 1 year upon denervation/nerve injury in the adult (Zelená, 1982, 1984). The exact mechanisms underlying this nerve-independent maintenance of adult Pacinian corpuscles are not known. Given the less severe phenotype of $\mathrm{Dhh}{ }^{\mathrm{Cre}} ; \mathrm{Er} 81^{\mathrm{fl}-} \mathrm{mu}-$ tant mice, we wondered whether neuronal factors may compensate for the loss of Er81 in Schwann cells and that its role in Schwann cells would be more obvious upon denervation. Thus, we performed unilateral tibial nerve transection on 2- to 4-month-old Dhh ${ }^{\mathrm{Cre}} ; \mathrm{Er}^{\mathrm{f}} \mathrm{1}^{\mathrm{fl}-}$ conditional mutants and $E r 81^{f /-}$ control mice, and examined Pacinian corpuscles 2 weeks after surgery. We confirmed denervation by the loss of $\mathrm{NFH}^{+}$fibers in Pacinian corpuscles (Fig. 4A-D). However, the number of corpuscles in the transected leg was similar to that of the contralateral nonoperated leg in both the controls and conditional mutants (Fig. 4E). This result indicates that Er81 is not necessary for the survival of Pacinian corpuscle Schwann cells following denervation.

\section{Er81 functions downstream of Ret in Pacinian corpuscle-innervating neurons} The common Pacinian corpuscle phenotype between Ret and Er81 mutants suggests that they may act in a common molecular pathway to promote corpuscle formation. If so, reducing the dosage of both genes may augment the effect on corpuscle formation. To test this idea, we examined the number of Pacinian corpuscles per leg in wild-type, $\operatorname{Ret}^{+/-}$, $\mathrm{Er} 81^{+/-}$, and $\mathrm{Ret}^{+/-} ; \mathrm{Er}^{+} 1^{+/-}$double-heterozygous mice. We found that Ret and Er81 single heterozygotes did not have a significant decrease in the number of Pacinian corpuscles relative to

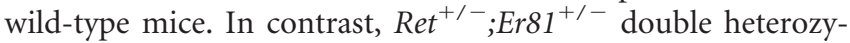
gotes had significantly fewer Pacinian corpuscles per leg than all other genotypes, and this deficit was greater than the additive deficit exhibited by Ret and Er81 single mutants (Fig. 5A). This result indicates that Ret and Er81 act in common or parallel pathways for Pacinian corpuscle formation during development.

How could RET and ER81 interact? In proprioceptors, Er81 expression is downstream of TrkC/NT3 neurotrophic signaling (Patel et al., 2003). Thus, we hypothesize that an analogous RET/ neurturin signaling pathway may control the expression of Er81 in Pacinian corpuscle-innervating RA mechanoreceptors. To test whether Ret regulates the expression of Er81, we performed double-fluorescent in situ hybridization against CFP (driven from the Ret locus) and Er81 in L4/L5 DRG sections. At E13.5, shortly after Er81 begins to be expressed in DRG neurons (Arber et al., 2000), we did not observe a change in the proportion of $\mathrm{CFP}^{+}$neurons that express Er81 in $\operatorname{Ret}^{\text {CFP/CFP }}$ mutants compared with Ret $^{C F P /+}$ controls (Fig. 5B-D). Therefore, Ret is not required for the initiation of Er81 expression in RA mechanoreceptors. We next examined the expression of Er81 at E16.5 and found that a smaller proportion of RA mechanoreceptors expressed Er81 in Ret mutants compared with controls, suggesting a requirement for RET signaling in maintaining the expression of Er81 at later embryonic stages (Fig. 5E-G).
One potential confound when examining the loss-of-function effects of neurotrophic factor signaling is neuronal death. It remains possible that decreases in Er81 expression in Ret mutants may be due to the death of specific subsets of RA mechanoreceptors. To investigate cell-survival independent effects of RET signaling on Er81 expression, we examined Ret mutants and controls in a Bax-null background, which blocks cell death caused by a lack of neurotrophic support (Patel et al., 2000). We found a significant decrease in the proportion of large-diameter $\mathrm{CFP}^{+}$neurons expressing Er81 in P0 Ret ${ }^{\mathrm{CFP} / C F P} ; \mathrm{Bax}^{-/-}$double mutants compared with $\mathrm{Ret}^{\mathrm{CFP} /+} ; \mathrm{Bax}^{-/-}$controls (Fig. $5 \mathrm{H}-\mathrm{J}$ ). Together, our results indicate that, similar to NT3/TrkC signaling in proprioceptors, RET signaling is required for the maintenance, but not initiation, of Er81 expression in RA mechanoreceptors.

Conversely, it is possible that Er81 regulates the expression of Ret. To examine this possibility, we performed Ret/TrkA doublefluorescent in situ hybridization combined with anti-NFH immunostaining with Er81 ${ }^{+/-} ; \mathrm{Bax}^{-/-}$control and $\mathrm{Er} 81^{-/-}$; $B a x^{-/-}$double-null L4/L5 DRG sections (Fig. 6A,B). We used the Bax-null background here as well because loss of DRG neurons during the early postnatal period in Er81 mutants has previously been reported (Kucera et al., 2002; de Nooij et al., 2013). We quantified the number of $\mathrm{Ret}^{+} / \mathrm{TrkA}^{-} / \mathrm{NFH}^{+} \mathrm{RA}$ mechanoreceptors per L4/L5 DRG section (Fig. $6 C$ ). We found that this number was not significantly different between Bax single-null controls and the Er81;Bax double mutants, suggesting that Er81 does not regulate the expression of Ret in RA mechanoreceptors. Collectively, our results place Er81 downstream of Ret in the pathway controlling Pacinian corpuscle formation. 

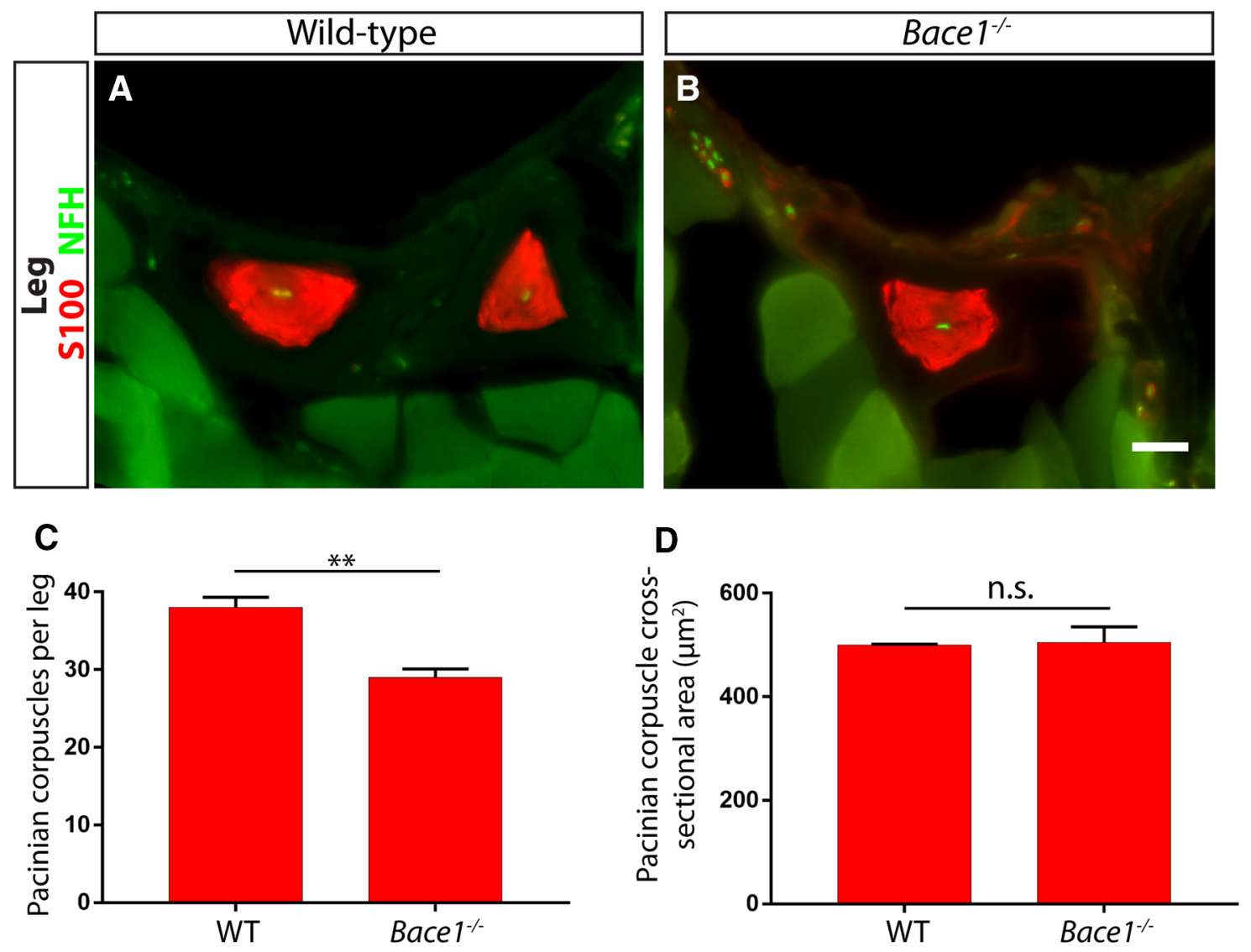

Figure 10. Bace1 contributes to the development of Pacinian corpuscles. $A, B$, Anti-S100 and anti-NFH staining with hindlimb sections of 3-to $4-$ week-old Bace ${ }^{+/+}$control $(\boldsymbol{A})$ and Bace $1^{-/-}$ mutant $(\boldsymbol{B})$ mice show Pacinian corpuscles around the fibula. C, Bace1-null mice have significantly fewer $\mathrm{S100}{ }^{+}$Pacinian corpuscles per leg quantified from serial hindlimb sections compared with wild-type littermate controls (Bace ${ }^{+/+}$mice have $38 \pm 1.31$ Pacinian corpuscles per leg, Bace ${ }^{-/-}$mice have $29 \pm 1.10$ Pacinian corpuscles per leg; $\left.p=0.006\right)$. D, The size of the remaining

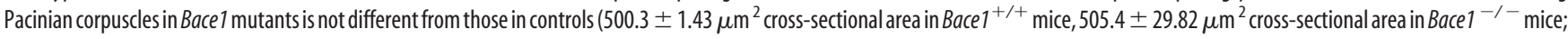
$p=0.87) . N=3$ animals, 6 legs per genotype. ${ }^{* *} p<0.01$. Not significant: $p \geq 0.05$. Error bars indicate SEM. Scale bar, $20 \mu \mathrm{m}$.

\section{Primary deficits of Pacinian corpuscle development in Ret and Er81 mutants}

What are the primary deficits in Ret and Er81 mutants that prevent Pacinian corpuscle formation? To determine whether the Ret Pacinian corpuscle phenotype is completely due to the death of Pacinian corpuscle-innervating neurons, we examined Ret $^{-1-} ; \mathrm{Bax}^{-1-}$ double mutants at P0, the latest time they survive. Because S100 is not yet expressed in immature Schwann cells at P0, we used H\&E staining of serial leg sections to visualize rudimentary Pacinian corpuscles. We found rudimentary corpuscles around the fibula of $\mathrm{Ret}^{\mathrm{CFP} /+} ; \mathrm{Bax}^{-/-}$control mice, but not in the Ret ${ }^{C F P / C F P} ; B a x^{-1-}$ double mutants (Fig. $7 A, B$ ). In addition, we performed immunostaining against CFP driven from the Ret locus to examine the axons of the interosseous nerve innervating Pacinian corpuscles. These axons were found adjacent to the fibula and proximal to the formation of Pacinian corpuscles in the $\operatorname{Ret}^{\mathrm{CFP/+}} ; \mathrm{Bax}^{-/-}$control mice but were absent in the Ret ${ }^{\text {CFP/CFP }} ; \mathrm{Bax}^{-1-}$ double mutants (Fig. 7C,D). Therefore, Pacinian corpuscle development is not initiated in Ret mutants, which is likely due to deficient axon guidance or growth of Pacinian corpuscle-innervating neurons in the absence of RET signaling.

Why do Pacinian corpuscles fail to form in Er81 mutants? We considered three potential functions of ER81 in neurons to control Pacinian corpuscle development. First, it is possible that $\mathrm{Pa}-$ cinian corpuscle-innervating neurons depend on Er81 for their survival. Second, similar to Ret mutants, Pacinian corpuscleinnervating neurons may not reach their target without Er81.
Last, if innervating neurons reach the proper target and Schwann cell precursors are present, a problem in communication between the axon and the Schwann cells could prevent corpuscle formation. To determine whether Er81 acts to promote neuronal survival to control Pacinian corpuscle formation, we performed anti-S100/anti-NFH immunostaining on Er81 mutant and control legs in a Bax-null background at P3 (Fig. 8A,B). We found that, although $\mathrm{S} 00^{+}$Pacinian corpuscles were present in the double mutants, they were more than halved in number and size (Fig. 8C,D). Additionally, the expression level of S100, which is a marker of Schwann cell maturation, was just above the threshold of detection in the double mutants and much weaker compared with that of the Er81 ${ }^{+/-} ; B a x^{-/-}$control corpuscles. Therefore, Er81 mutants have defects in Pacinian corpuscle development other than cell death. In addition, because all corpuscles were innervated by $\mathrm{NFH}^{+}$axons in controls, Er81 ${ }^{-/-}$single-null (Fig. $8 E, F)$ and $E r 81^{-/-} ; \mathrm{Bax}^{-/-}$double mutants, our results also suggest that targeting and growth of Pacinian corpuscle axons are largely unaffected in the absence of Er81.

If innervating axons reach their target in Er81 mutants, do they begin the process of generating Pacinian corpuscles? We performed H\&E and anti-S100/anti-NFH staining on P2 leg serial sections. In $\mathrm{Er} 81^{+/-}$controls, we observed well-formed rudimentary corpuscles by H\&E staining. In addition, Schwann cells surrounding innervating fibers started to express high levels of S100, a marker of mature Schwann cells. In contrast, Er81nulls had hypotrophic rudimentary Pacinian corpuscles by $\mathrm{H} \& \mathrm{E}$ 

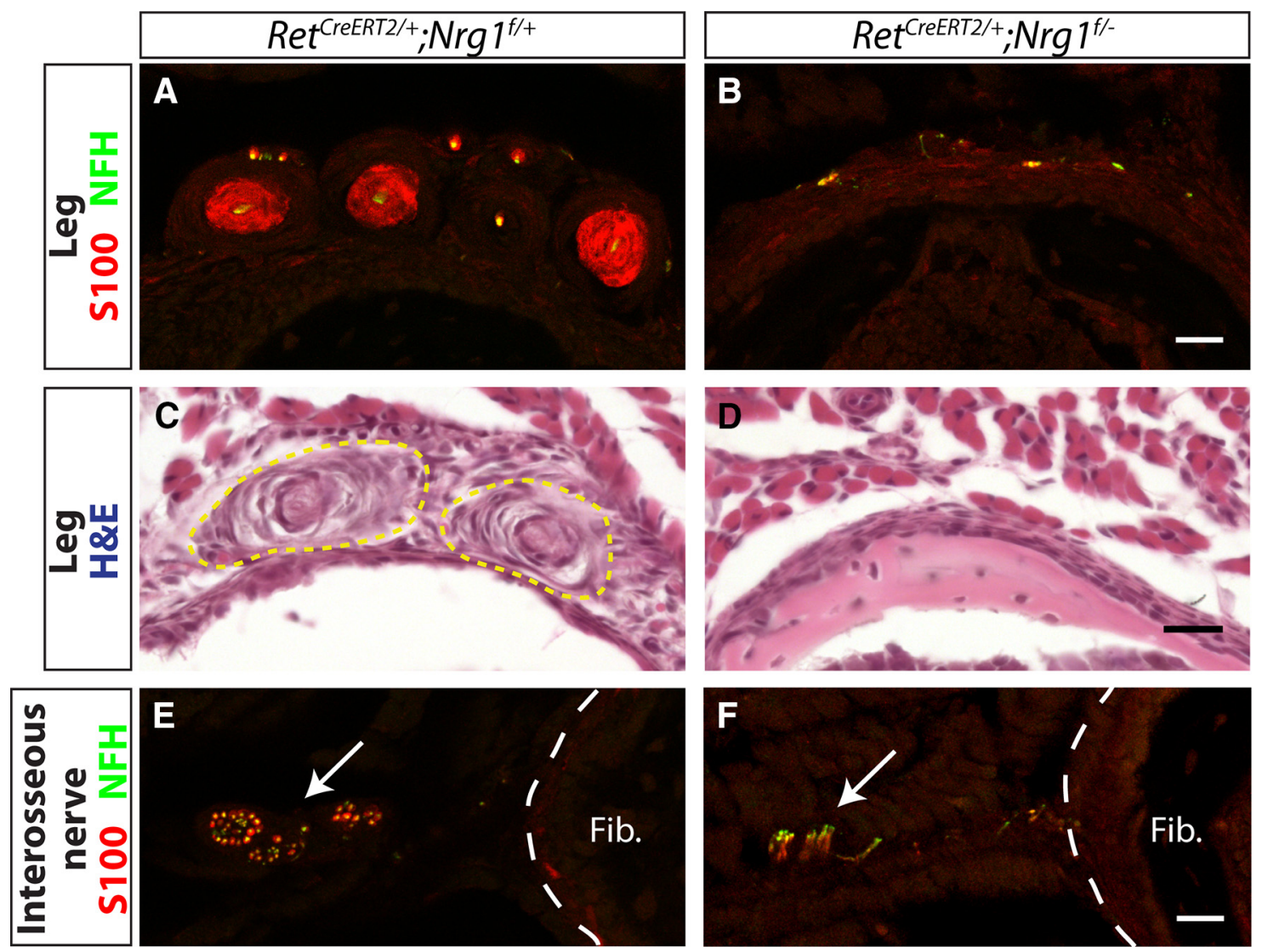

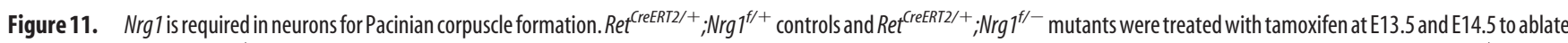
$\mathrm{Nrg} 1$ conditional allele in Ret ${ }^{+}$cells, including Pacinian corpuscle-innervating neurons. $A, B$, Anti-S100 (red) and anti-NFH (green) staining of P5 hindlimb sections shows a lack of $S 100{ }^{+}$Pacinian corpuscles in the $\mathrm{Nrg} 1$ conditional mutant mice. $\boldsymbol{C}, \boldsymbol{D}, \mathrm{H} \& \mathrm{E}$-stained hindlimb sections show a lack of Pacinian corpuscle-like Schwann cell structures in Nrg1 conditional mutant mice. $\boldsymbol{E}$, $\boldsymbol{F}$, S100/NFH staining of hindlimb sections proximal to the appearance of Pacinian corpuscles around the fibula shows axons of the interosseous nerve, which innervate Pacinian corpuscles, present in both mutant and control mice. $N=3$ animals, 6 legs per genotype. Scale bar, $20 \mu \mathrm{m}$.

staining, whereas Pacinian corpuscle-like anti-S100 staining was not present around the $\mathrm{NFH}^{+}$axons innervating the fibula (Fig. $8 G-J)$. This lack of mature Schwann cell phenotype is very similar to that of P3 Er81 ${ }^{-/-} ; \mathrm{Bax}^{-/-}$double-mutant mice. Collectively, our results indicate that Er81 mutant Pacinian corpuscleinnervating axons reach their target and initiate the development of Pacinian corpuscles. However, Schwann cells of these rudimentary corpuscles do not properly differentiate to form mature Pacinian corpuscles. Given the absolute requirement of Er81 in neurons to control Pacinian corpuscle development (Fig. 3A-F), these phenotypes suggest that ER81 may play critical roles in innervating axons to communicate with the corpuscle-forming Schwann cells. Our analysis of Ret and Er81 mutant Pacinian corpuscle phenotypes also supports the idea that RET functions upstream of ER81 in this pathway.

\section{Normal myelination in Er81 mutants}

Given the Pacinian corpuscle phenotype of Er81 mutant mice and Er81 expression in myelinating Schwann cells (Srinivasan et al., 2007), we asked whether the development of the most prevalent Schwann cell type in the PNS, myelinating Schwann cells, is also affected by the ablation of Er81. To answer this question, we performed transmission electron microscopy on L5 dorsal roots of $\mathrm{ErB1}^{+/-}$controls and $\mathrm{Er} 81^{-1-}$ mutants and calculated the g-ratio of individual axonal fibers (Fig. 9). At P21, which is near the maximum lifespan of Er81 mutants, there was no significant difference in the g-ratio between controls and mutants, and there were no obvious defects in the morphology of the myelin sheath. Therefore, in contrast to its critical role for Pacinian corpuscle formation, Er81 does not seem to be required for development of myelinating Schwann cells, proper myelination, or for communication between axons and myelinating Schwann cells.

\section{Nrg1 is required in RA mechanoreceptors for Pacinian corpuscle formation}

Because ER81 is a transcription factor, it is unlikely that it acts directly in the communication between axons and nonmyelinating Schwann cells. Which molecules could function downstream of ER81 to mediate this action? Pacinian corpuscle-innervating neurons express NRG1, whereas corpuscle Schwann cells express the NRG1 receptors ERBB2 and ERBB3 (Kopp et al., 1997; González-Martínez et al., 2007). However, it is unclear whether NRG1 signaling contributes to Pacinian corpuscle formation during development.

The juxtamembrane regions of both NRG1-CRD and NRG1-Ig can be cleaved by proteases (Nave and Salzer, 2006; Fleck et al., 2013), which may potentiate the ability of the EGF domain of NRG1 to interact with ERBB receptors. $\beta$-secretase 1 is one of the proteases, which cleaves NRG1 and contributes to the promyelinating and promuscle spindle development roles of Nrg1-CRD and Nrg1-Ig, respectively (Hu et al., 2006; Willem et al., 2006; Cheret et al., 2013). Thus, we first examined the legs of Bace1-nulls and littermate controls. We found a significant decrease in the number of Pacinian corpuscles per leg, but no dif- 

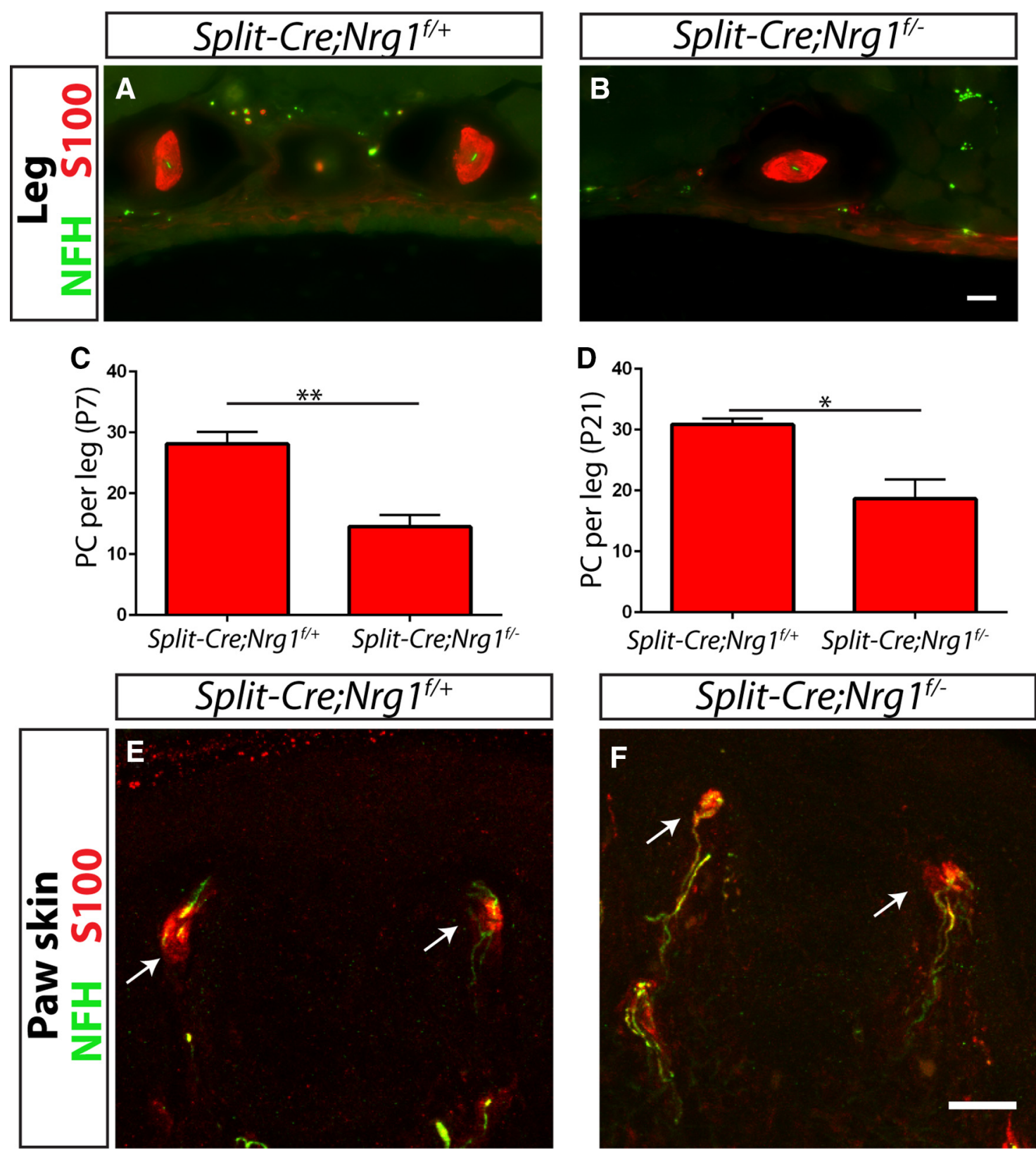

Figure 12. Neuronal $\mathrm{Nrg} 1$ is required for Pacinian, but not Meissner, corpuscle development. $\boldsymbol{A}-\boldsymbol{D}$, Split ${ }^{\text {(re }}$, which drives recombination in RA mechanoreceptors, produced a partial, but significant, decrease in the number of Pacinian corpuscles per leg when combined with a conditional Nrg1 allele at both P7 (data not shown; $C)$ and P21 (A, B, D) (Split ${ }^{\mathrm{Cre}} ; \mathrm{Nrg} 7^{f /+}$ controls have

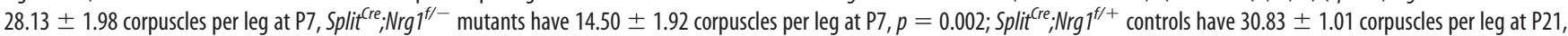

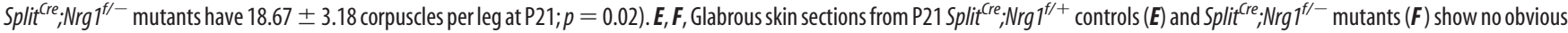
change in the appearance or number of Meissner corpuscles in mutants relative to controls. $N=3$ animals, 6 legs/glabrous skin samples per genotype. ${ }^{*} p<0.05$. ${ }^{* *} p<0.01$. Error bars indicate SEM. Scale bar, $20 \mu \mathrm{m}$.

ference in the average size of individual corpuscles (Fig. 10). A decrease in number, rather than a total absence of corpuscles, is in line with partial reductions in myelination and muscle spindle formation observed in Bace1 mutants (Hu et al., 2006; Willem et al., 2006; Cheret et al., 2013). This phenotype suggests that Nrg1 may be required for Pacinian corpuscle formation.

To determine whether neuronal $\mathrm{Nrg} 1$ expression is required for Pacinian corpuscle formation, we ablated Nrgl from RA mechanoreceptors by combining a floxed allele of Nrg1 with a tamoxifen-inducible $\operatorname{Ret}^{\mathrm{Cr} E \mathrm{ERT} 2}$ line (Luo et al., 2009). We treated these mice with tamoxifen at E13.5 and E14.5 to avoid early embryonic requirements for Nrg1 in DRG neuron survival and cardiovascular development. At P5, Pacinian corpuscles and innervating axons were present in the Ret ${ }^{\mathrm{CreERT2}} ; \mathrm{Nrg}^{\mathrm{fl+}}$ control mouse legs, whereas in $\mathrm{Ret}^{\mathrm{CreERT2}} ; \mathrm{Nrg}^{f /-}$ conditional mutant legs, $\mathrm{S}_{100}{ }^{+}$Pacinian corpuscles were completely absent (Fig. 11 A,B). As expression of molecular markers, such as $\$ 100$, may be altered in the mutant background, we also confirmed the absence of Pacinian corpuscle structures in conditional mutants by $\mathrm{H} \& \mathrm{E}$ staining (Fig. $11 C, D$ ). Interestingly, $\mathrm{NFH}^{+}$innervating axons persisted, suggesting that Pacinian corpuscle axons reach their target and survive until at least P5 when Nrg1 expression is ablated (Fig. $11 E, F$ ). Therefore, similar to Er81, Nrg1 is not required for axon pathfinding of Pacinian corpuscle neurons but likely functions to mediate communication between axons and corpuscle-forming Schwann cells. 

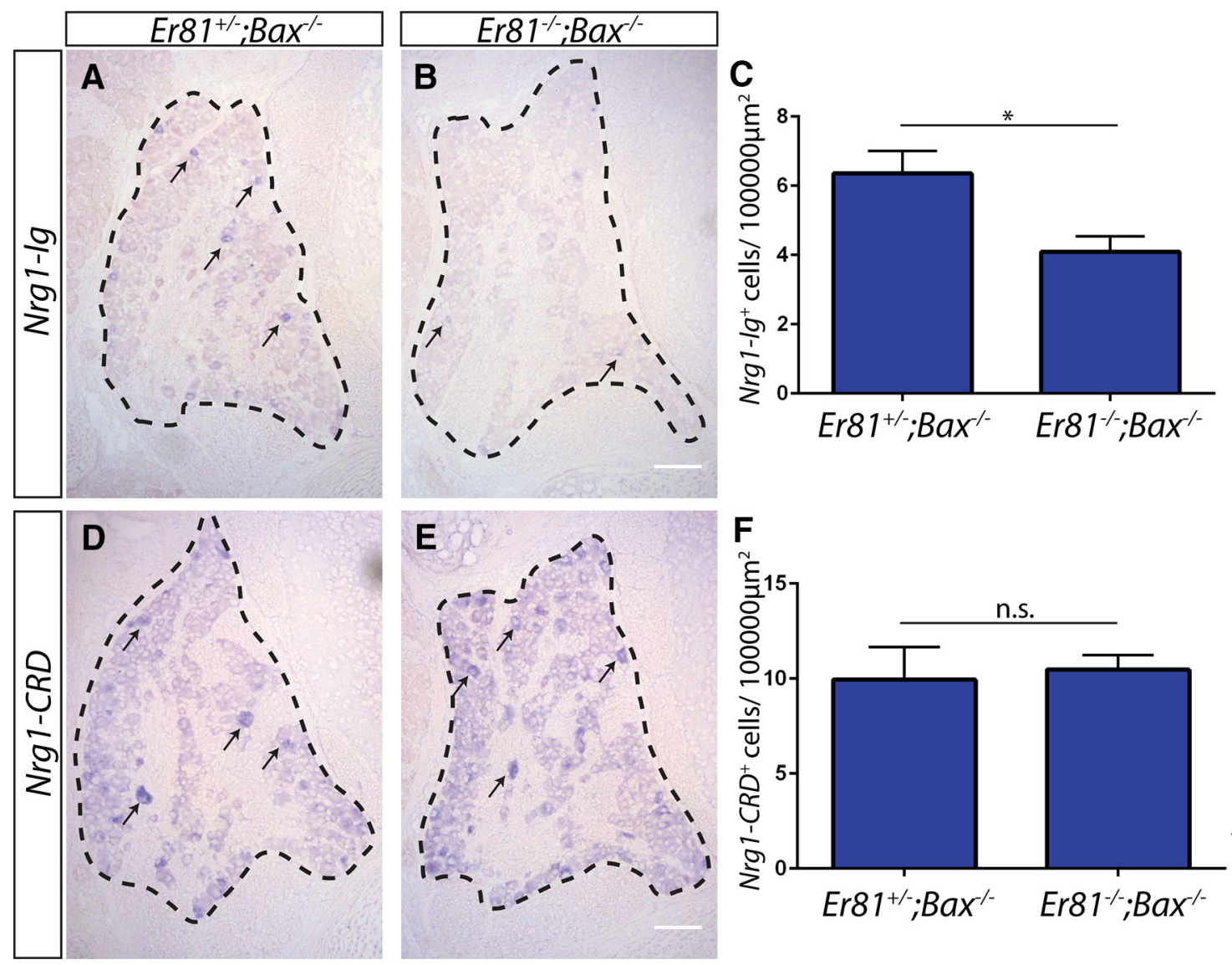

Figure 13. Er81 regulates the expression of Nrg1-Ig, but not Nrg1-CRD, in DRG neurons. A-C, Isoform-specific in situ hybridization against Nrg1-Ig shows a significant decrease in the number of cells expressing Nrg1-Ig transcript in L4/L5 DRGs from P3-P5 Er81 mutants in an apoptosis-deficient background relative to controls (6.36 $\pm 0.65 \mathrm{Nrg}^{-1 g}{ }^{+}$cells per 100,000 $\mu \mathrm{m}^{2}$ in Er81 ${ }^{+/-}$; $\mathrm{Bax}^{-1-}$ controls, $4.09 \pm 0.48 \mathrm{Nrg} 1-\mathrm{Ig}^{+}$cells per $100,000 \mu \mathrm{m}^{2}$ in Er81 ${ }^{+/-} ; B a x^{-\prime-}$ controls; $\left.p=0.04\right)$. Some positive cells are indicated by arrows. D-F, Isoform-specific in situ hybridization

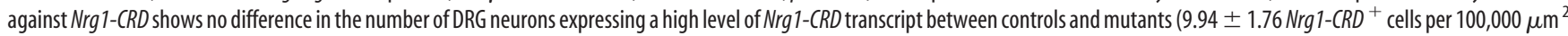

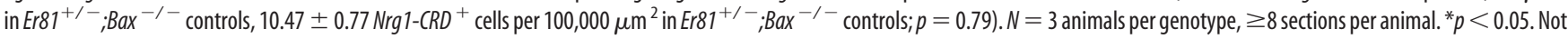
significant: $p \geq 0.05$. Error bars indicate SEM. Scale bar, $100 \mu \mathrm{m}$.

To confirm the neural requirement for $\mathrm{Nrg} 1$ in Pacinian corpuscle formation, we also ablated Nrg1 from mechanosensory neurons using a Split ${ }^{\mathrm{Cre}}$ transgenic line, which also drives recombination in RA mechanoreceptors (Rutlin et al., 2014). At P7 and $\mathrm{P} 21, \mathrm{Split}^{\mathrm{Cre}} ; \mathrm{Nrgl}^{\mathrm{f} /-}$ conditional mutants have approximately half the number of Pacinian corpuscles of Split ${ }^{\mathrm{Cre}} ; \mathrm{Nrg}^{\mathrm{ff+}}$ control mice (Fig. 12A-D). The incomplete phenotype observed in Split ${ }^{C r e}$ conditional mutants may be caused by incomplete ablation of $\mathrm{Nrg1}$ in mechanosensory neurons due to transient or low-level expression of recombinase, or due to a late ablation of Nrg1 in some neurons after a critical period. In addition, no obvious defects of Meissner corpuscles were found in P21 Split ${ }^{\text {Cre }}$; $\mathrm{Nrg}^{f /-}$ conditional mutants (Fig. 12 E, F), suggesting that Meissner corpuscles do not depend on neuronal $\mathrm{Nrg} 1$ for their end organ formation. Thus, Nrg1 is specifically required in RA mechanoreceptors for Pacinian corpuscle development.

\section{Nrg1-Ig expression is reduced in Er81-null DRG neurons}

Given the very similar Pacinian corpuscle phenotypes in Er81null and $\mathrm{Nrg} 1$ conditional-null mutants, we asked whether Er81 regulates the expression of $\mathrm{Nrg}$. We performed isoform-specific in situ hybridization for Nrg1-Ig and Nrg1-CRD transcripts. We found that the expression of Nrg1-Ig, but not Nrg1-CRD, transcript was reduced in Er81;Bax double-null L4/L5 DRGs (Fig. 13), suggesting that Er81 specifically regulates Nrg1-Ig expres- sion. This finding is in agreement with the g-ratio data, which showed no deficits in myelination in Er81 mutants (Fig. 9). Given the tight correlation between myelination and Nrg1-CRD expression (Michailov et al., 2004), it also seems unlikely that Nrg1CRD expression would be reduced in Er81 mutants.

To further investigate a potential role for NRG1-CRD in Pacinian corpuscle development, we examined Pacinian corpuscle formation in Nrg1-CRD ${ }^{+/-}$heterozygotes and wild-type littermate controls at P21. Nrg1-CRD-null mice die around birth and have high levels of somatosensory neuron cell death (Wolpowitz et al., 2000), making the examination of Pacinian corpuscles difficult to interpret. $\mathrm{Nrg1-CRD^{+/- }}$ heterozygotes survive to adulthood and have a large decrease in the level of myelination of peripheral nerves. If the dose-dependent requirement for NRG1CRD is similar between myelinating Schwann cells and nonmyelinating Pacinian corpuscle Schwann cells, then Nrg1-CRD heterozygotes may display some deficits in the number or size of Pacinian corpuscles. However, we found that the size and number of Pacinian corpuscles were not significantly different between $\mathrm{Nrg1-CRD^{+- }}$ and wild-type mice (Fig. 14). Therefore, unlike myelinating Schwann cells, Pacinian corpuscle Schwann cells do not require high levels of $\mathrm{Nrg1-CRD}$ expression for their development. In combination with the Nrg1 mutant phenotype and Nrg1 isoform-specific in situ data from Er81 mutant mice, this result suggests that ER81 in Pacinian corpuscle-innervating 

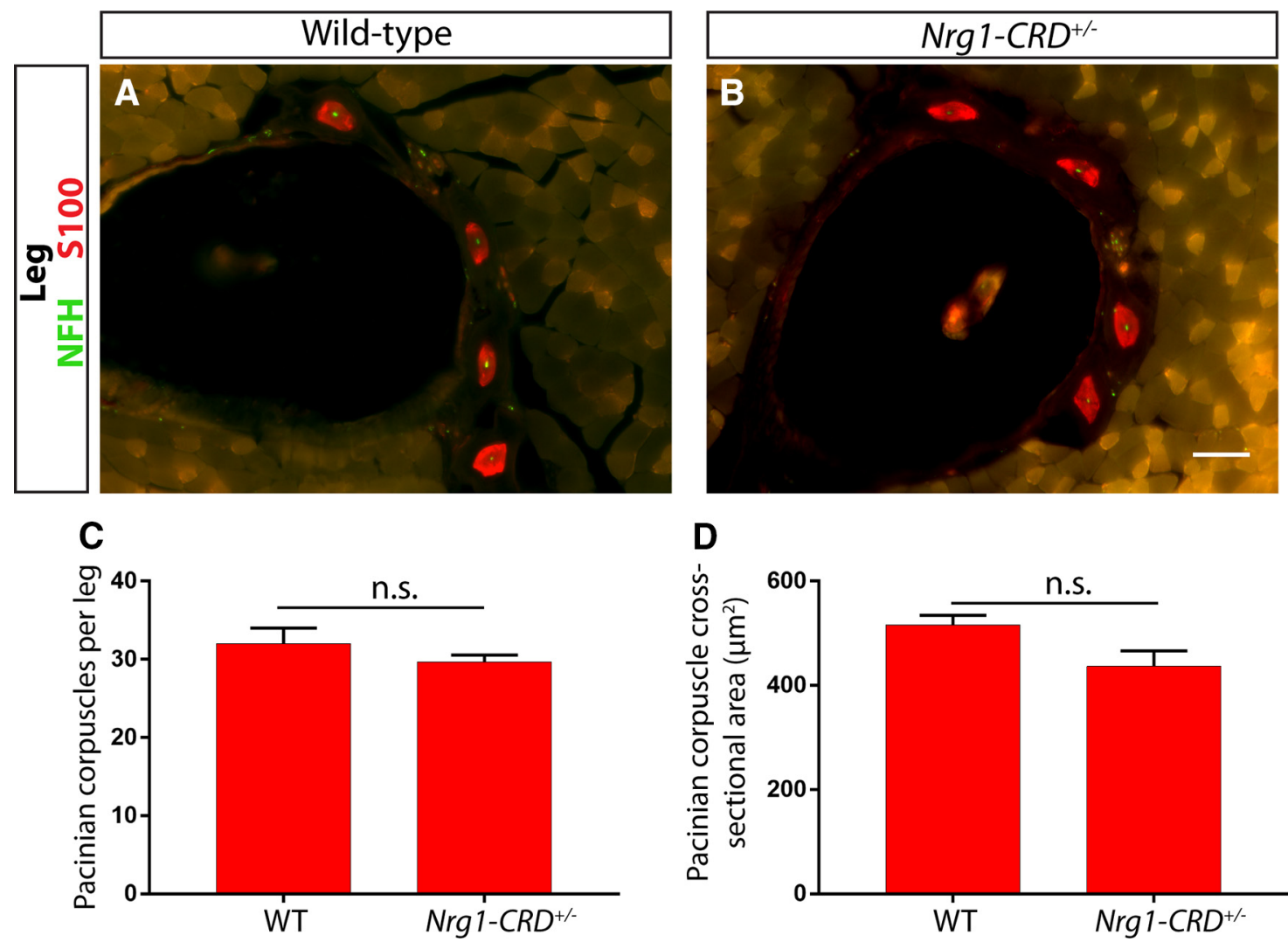

Figure 14. A high level of NRG1-CRD is not required for Pacinian corpuscle development. $A, B$, Anti-S100 (red) and anti-NFH (green) staining with hindlimb sections of P21 Nrg1-CRD ${ }^{+/+}(\boldsymbol{A})$ and

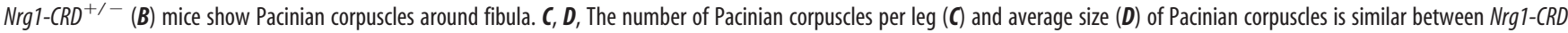
heterozygotes and wild-type littermate controls (Nrg1-CRD ${ }^{+/+}$mice have $32 \pm 2$ Pacinian corpuscles per leg, Nrg1-CRD ${ }^{+/-}$mice have $29.67 \pm 0.88$ Pacinian corpuscles per leg; $p=0.35$; $516.5 \pm 18.33 \mu \mathrm{m}^{2}$ cross-sectional area in Nrg1-CRD ${ }^{+/+}$mice, $436.6 \pm 29.57 \mu \mathrm{m}^{2}$ cross-sectional area in Nrg1-CRD ${ }^{+/-}$mice; $\left.p=0.08\right) . N=3$ animals, 6 legs per genotype. Not significant: $p \geq 0.05$. Error bars indicate SEM. Scale bar, $50 \mu \mathrm{m}$.

neurons regulates expression of $\mathrm{Nrg1}$, likely $\mathrm{Nrg1-Ig}$, to communicate with nonmyelinating Schwann cells and thus promote $\mathrm{Pa}$ cinian corpuscle formation.

\section{$\mathrm{Nrg1}$ in Schwann cells is not required for Pacinian corpuscle maintenance following injury}

Last, although Nrg1 is not normally expressed at detectable levels in Schwann cells, it has been reported that myelinating Schwann cells begin to express $\mathrm{Nrgl}$ following nerve injury, and that autocrine NRG1 signaling allows for the redifferentiation of Schwann cells following denervation (Carroll et al., 1997; Stassart et al., 2013). This Schwann cell-derived NRG1 signaling is critical for nerve regeneration and remyelination. Thus, we investigated whether a similar mechanism exists in Pacinian corpuscle nonmyelinating Schwann cells upon denervation/nerve injury. We generated Schwann cell-specific $\mathrm{Dhh}^{\mathrm{Cre}} ; \mathrm{Nrg} 1^{\mathrm{fff}}$ mutants and observed no obvious deficits in Pacinian corpuscle number or morphology at P7 (data not shown). We performed unilateral tibial nerve transection on adult controls and conditional mutants and confirmed denervation by a lack of $\mathrm{NFH}^{+}$innervating fibers. We observed no decrease in the number of corpuscles per leg in the denervated leg relative to the contralateral leg even 3 months after surgery (Fig. 15). Our results suggest that the cellular mechanisms supporting regeneration upon nerve injury also differ between myelinating and nonmyelinating Schwann cells.

\section{Discussion}

Nonmyelinating Schwann cells are an important component of the PNS, but how they communicate with neurons has remained largely unclear. In this study, we have used mouse Pacinian corpuscles as a model to investigate axonal interactions with nonmyelinating Schwann cells and identified a signaling pathway that specifically functions in this process.

Previous studies have shown that the receptor tyrosine kinase Ret and the ETS transcription factor Er81 both are required for the development of Pacinian corpuscles (Sedý et al., 2006; Luo et al., 2009). However, the mechanisms underlying ER81 function in this regard are unclear. Here, we have shown that Er81 is expressed and required in Pacinian corpuscle-innervating neurons (Fig. 3), Er81 and Ret genetically interact (Fig. 5) to control Pacinian corpuscle development, and Er81 expression in RA mechanoreceptors is partly controlled by Ret (Fig. 5). One minor difference between our results and the previous study (Sedý et al., 2006) is that we found Pacinian corpuscle afferents and nascent Pacinian corpuscles are present at P2 in Er81 mutants, whereas the previous study suggested that they are not present in mutants from E16.5 to P1. This discrepancy is likely due to the different methods used for detecting Pacinian corpuscles and their afferents between the previous study and our own, or differences in the genetic backgrounds of the mice that may affect the timing or severity of the phenotypes. In addition, we found that Nrg1, a major mediator of axon-Schwann cell communication, is also required in RA mechanoreceptors for Pacinian corpuscle formation, and that ER81 may control the expression of Nrg1-Ig to promote Pacinian corpuscle formation (Fig. 13). Thus, our results establish a RET-ER81-NRG1 pathway in neurons to promote Pacinian corpuscle end organ formation (Fig. 16). 

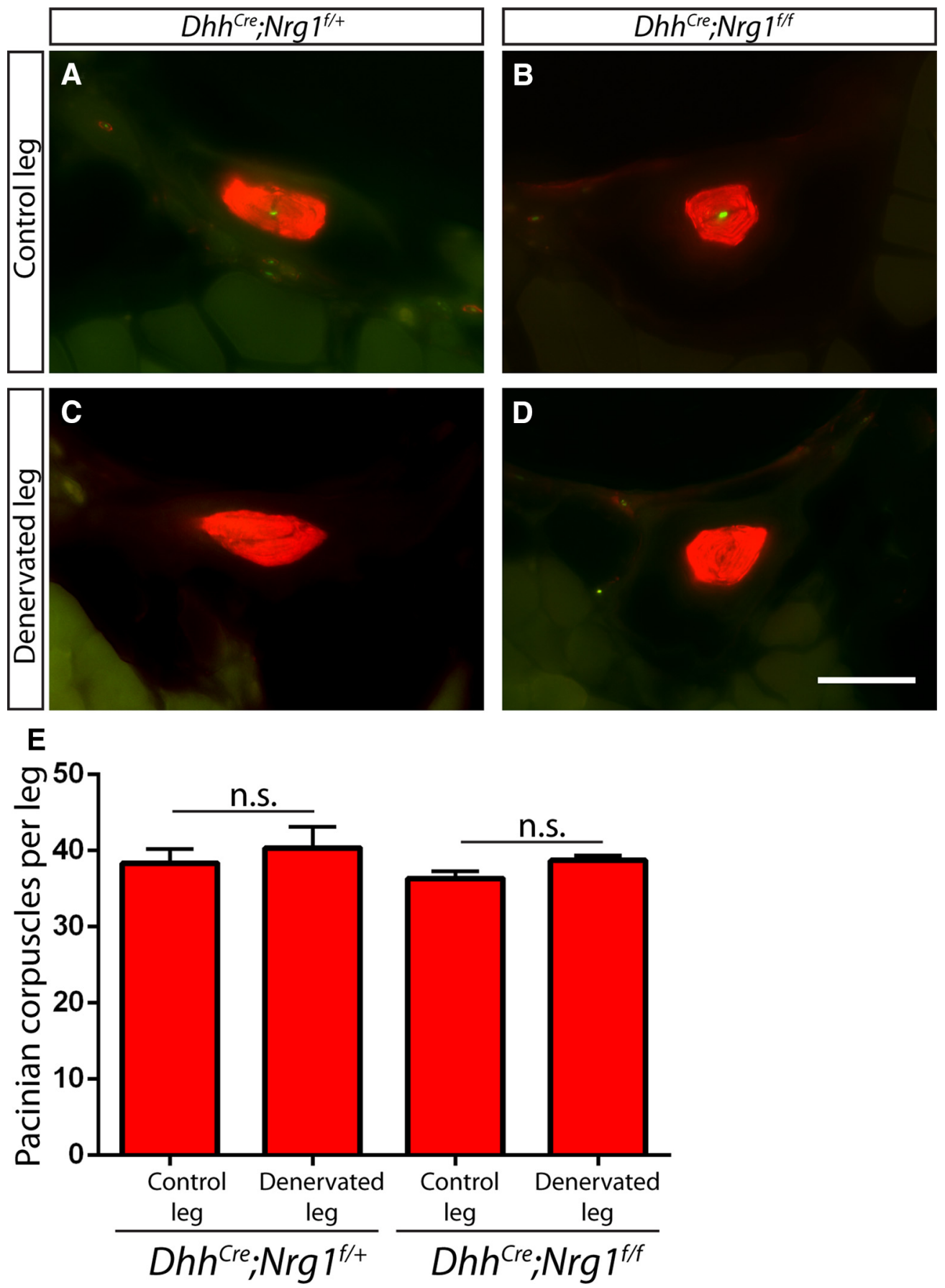

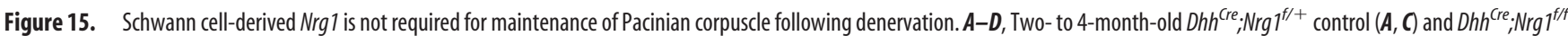
conditional mutants $(\boldsymbol{B}, \boldsymbol{D})$ underwent unilateral tibial nerve transection and recovered for 3 months before tissue processing. $\mathrm{NFH}^{+}$(green) innervating fibers were present in the $\mathrm{S} 100^{+}$(red) corpuscle inner cores of cross-sections of nonsurgical limbs $(\boldsymbol{A}, \boldsymbol{B})$ but were absent from corpuscle inner cores of denervated limbs $(\boldsymbol{C}, \boldsymbol{D})$. $\boldsymbol{E}$, Quantification of $S 100^{+}$Pacinian corpuscles in serial

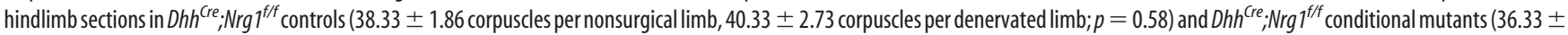
0.88 corpuscles per nonsurgical limb, $38.67 \pm 0.67$ corpuscles per denervated limb; $p=0.10$ ) shows that loss of $\mathrm{Nrg} 1$ in Schwann cells does not cause a deficit in the maintenance of Pacinian corpuscles following denervating injury. $N=3$ legs per condition. Not significant: $p \geq 0.05$. Error bars indicate SEM. Scale bar, $50 \mu \mathrm{m}$.

Our results also suggest that neurons may use different molecules, such as different isoforms of NRG1, to communicate with myelinating versus nonmyelinating Schwann cells. It is remarkable that Pacinian corpuscles are completely absent in Er81 mutant mice due to a deficit of axon-Schwann cell communication while myelination seems normal (Figs. 8, 9). This phenotype is consistent with the fact that expression of Nrg1-CRD, the NRG1 isoform-specific for myelination thickness, is normal in Er81 mutants and that there is no Pacinian corpuscle phenotype in Nrg1-CRD heterozygous mice.
However, it remains an open question whether Nrg1-Ig is the key or only isoform required for Pacinian corpuscle development. It was mentioned that Pacinian corpuscles are present in Nrg1-Ig conditional mutants (Cheret et al., 2013), but the data were not shown and the age of examination was not described. Therefore, more careful analysis is needed for Nrg1-Ig conditional mutants. Alternatively, it is possible that multiple isoforms of NRG1 are sufficient to drive Pacinian corpuscle formation, and eliminating individual isoforms will not produce a serious deficit in corpuscle development. 


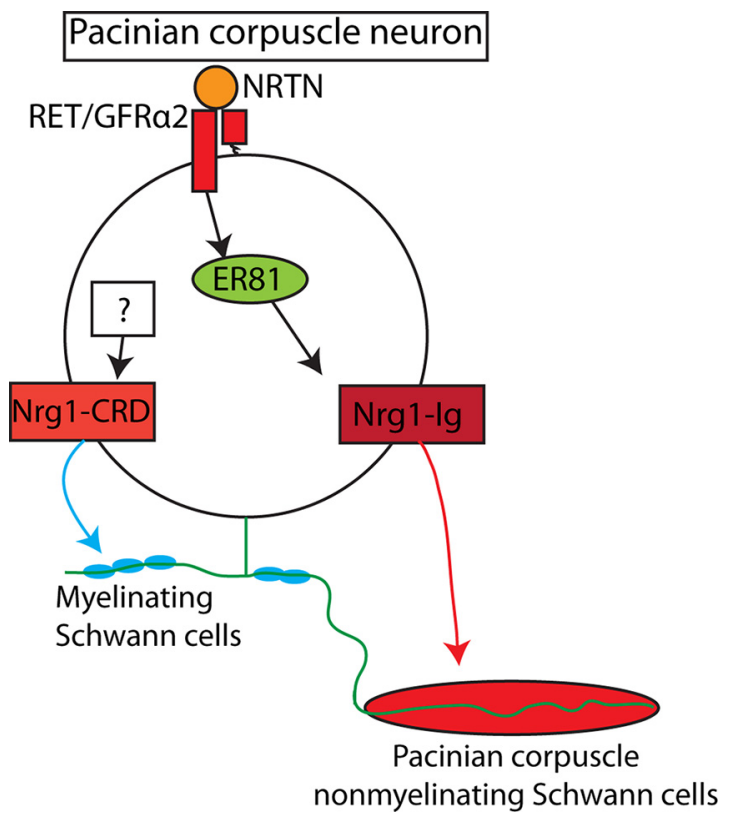

Figure 16. The roles of RET signaling, ER81, and NRG1 in Pacinian corpuscle development. In Pacinian corpuscle-innervating neurons, the expression of ER81 lies downstream of RET/ GFR $\alpha 2 /$ NRTN signaling. ER81 regulates the expression of some Nrg1 isoforms, including Nrg1-lg, which is required for communicating with corpuscle-forming Schwann cells and thus the formation of Pacinian corpuscle end organs. Another isoform of NRG1, NRG1-CRD, is critical for interactions with myelinating Schwann cells (Michailov et al., 2004), but the upstream transcriptional regulators remain unknown.

Moreover, although the signaling pathways in Schwann cells activated by NRG1 have been extensively studied (Newbern and Birchmeier, 2010; Salzer, 2015), how the isoform-specific expression, as well as expression level, of $\mathrm{Nrgl}$ is regulated in neurons is completely unknown. Although Er81 and Nrg1 mutant mice display very similar muscle spindle phenotypes (Arber et al., 2000; Hippenmeyer et al., 2002), they have not been previously linked in the same pathway. The similar Pacinian corpuscle phenotype of Er81 and Nrg1 mutant mice and our isoform-specific Nrg1 in situ data (Figs. 11, 13) strongly suggest that ER81 may specifically

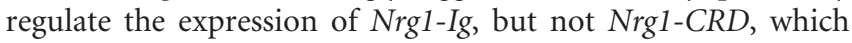
provides the first potential transcriptional regulator for $\mathrm{Nrgl}$ as far as we know. Further studies to determine how ER81 and other factors control the expression level of $\mathrm{Nrgl}$ in different cell types may assist in understanding not only axon-Schwann cell interactions in the PNS, but also etiology of diseases, such as schizophrenia, in which disruption of $\mathrm{Nrgl}$ expression has been implicated (Mei and Nave, 2014).

\section{Neurotrophic factor signaling, ER81, and NRG1 in somatosensory neurons}

Our findings also raise interesting parallels with proprioceptors, another major class of somatosensory neurons. Er81 is required in proprioceptors to establish appropriate connections with motor neuron targets in the spinal cord (Arber et al., 2000). Similar to the observed Er81-null Pacinian corpuscle phenotype, the initial proprioceptive projections to the periphery are normal in Er81 mutants, but the morphology and specification of proprioceptive end organs go awry in the early postnatal period (Arber et al., 2000; Kucera et al., 2002). In addition, proprioceptors are highly dependent on TrkC/NT3 signaling for their survival and development (Klein et al., 1994; Tessarollo et al., 1994), and TrkC/NT3 signaling is necessary and sufficient to drive ER81 expression in proprioceptors (Patel et al., 2003). Pacinian corpuscle-innervating neurons express the neurotrophic factor receptor RET, and RET signaling components are required for the formation of Pacinian corpuscles. In Ret mutants, we found that the expression of Er81 is significantly reduced in RA mechanoreceptors. Therefore, these two distinct classes of neuron use distinct neurotrophic signaling pathways to converge on a similar cellular output of ER81 expression. Notably, the Er81-null proprioceptive and Pacinian corpuscle phenotypes are less severe than the NT3 ${ }^{-/-} ; \mathrm{Bax}^{-/-}$(Patel et al., 2003) and $\mathrm{Ret}^{-/-}$; $\mathrm{Bax}^{-/-}$phenotypes (Fig. 7), suggesting that neurotrophic signaling engages additional mediators other than Er81 in both cell types. Last, both proprioceptors and Pacinian corpuscles have similar reliance on $\mathrm{Nrg} 1$ for the development of their respective end organs. In neural-specific Nrg1 mutants, early stages of muscle spindle induction do not occur (Hippenmeyer et al., 2002). The enriched expression of Nrg1-Ig in proprioceptive neurons and examination of isoform-specific Nrgl mutants suggest that Nrg1-Ig, but not Nrg1-CRD, is required for muscle spindle development (Hippenmeyer et al., 2002; Cheret et al., 2013). Here, we have shown that Pacinian corpuscles do not form when Nrg1 is ablated from RA mechanoreceptors and Nrg1-CRD may not to be required in this process as well. Taken our data and previous publications into consideration, it seems possible that Er81 specifically controls the expression of $\mathrm{Nrg1}$ - Ig and/or other isoforms in both proprioceptors and Pacinian corpuscle-innervating neurons to control proper end organ development of both types.

In addition to RET, Pacinian corpuscle afferents express additional receptor tyrosine kinases, such as TrkC (Sedý et al., 2004), although there is only a small decrease in the number of Pacinian corpuscles in TrkC mutants (Sedý et al., 2004; de Carlos et al., 2006). Nevertheless, as both RET and TrkC promote Er81 and Nrg1 expression (Hippenmeyer et al., 2002), it is possible that RET and TrkC signaling may activate common downstream pathways in DRG neurons to promote Pacinian corpuscle development.

Last, both Pacinian and Meissner corpuscles are formed by RA mechanosensory axons and nonmyelinating Schwann cells. Both types of neurons develop from the early RET $^{+}$DRG neurons and display rapidly adapting and low-threshold mechanosensitivity. However, Pacinian corpuscles have large multilayer corpuscles, whereas Meissner corpuscles have small incomplete corpuscles. This difference is very important as it not only gives rise to different end organ morphologies but contributes to their physiological properties and optimal vibration detection frequencies (Loewenstein and Skalak, 1966). Given the known correlation between Nrg1 expression level and myelination thickness, it is interesting to speculate that the ER81-NRG1 pathway we found here is a key molecular mechanism to differentiate Pacinian corpuscles from Meissner corpuscles. Future gain-of-function experiments to overexpress Er81 or Nrg1 in Meissner corpuscleinnervating neurons would help to test this idea.

\section{References}

Arber S, Ladle DR, Lin JH, Frank E, Jessell TM (2000) ETS gene Er81 controls the formation of functional connections between group Ia sensory afferents and motor neurons. Cell 101:485-498. CrossRef Medline

Birchmeier C, Nave KA (2008) Neuregulin-1, a key axonal signal that drives Schwann cell growth and differentiation. Glia 56:1491-1497. CrossRef Medline

Bourane S, Garces A, Venteo S, Pattyn A, Hubert T, Fichard A, Puech S, Boukhaddaoui H, Baudet C, Takahashi S, Valmier J, Carroll P (2009) Low-threshold mechanoreceptor subtypes selectively express MafA and are specified by Ret signaling. Neuron 64:857-870. CrossRef Medline 
Carroll SL, Miller ML, Frohnert PW, Kim SS, Corbett JA (1997) Expression of neuregulins and their putative receptors, ErbB2 and ErbB3, is induced during Wallerian degeneration. J Neurosci 17:1642-1659. Medline

Chen X, Ye H, Kuruvilla R, Ramanan N, Scangos KW, Zhang C, Johnson NM, England PM, Shokat KM, Ginty DD (2005) A chemical-genetic approach to studying neurotrophin signaling. Neuron 46:13-21. CrossRef Medline

Cheret C, Willem M, Fricker FR, Wende H, Wulf-Goldenberg A, Tahirovic S, Nave KA, Saftig P, Haass C, Garratt AN, Bennett DL, Birchmeier C (2013) Bacel and Neuregulin-1 cooperate to control formation and maintenance of muscle spindles. EMBO J 32:2015-2028. CrossRef Medline

Danielian PS, Muccino D, Rowitch DH, Michael SK, McMahon AP (1998) Modification of gene activity in mouse embryos in utero by a tamoxifeninducible form of Cre recombinase. Curr Biol 8:1323-1326. CrossRef Medline

de Carlos F, Cobo J, Germanà G, Silos-Santiago I, Laurà R, Haro JJ, Fariñas I, Vega JA (2006) Abnormal development of pacinian corpuscles in double trkB;trkC knockout mice. Neurosci Lett 410:157-161. CrossRef Medline

de Nooij JC, Doobar S, Jessell TM (2013) Etvl inactivation reveals proprioceptor subclasses that reflect the level of NT3 expression in muscle targets. Neuron 77:1055-1068. CrossRef Medline

Fleck D, van Bebber F, Colombo A, Galante C, Schwenk BM, Rabe L, Hampel H, Novak B, Kremmer E, Tahirovic S, Edbauer D, Lichtenthaler SF, Schmid B, Willem M, Haass C (2013) Dual cleavage of neuregulin 1 type III by BACE1 and ADAM17 liberates its EGF-like domain and allows paracrine signaling. J Neurosci 33:7856-7869. CrossRef Medline

Fleming MS, Luo W (2013) The anatomy, function, and development of mammalian Abeta low-threshold mechanoreceptors. Front Biol (Beijing) 8:4. CrossRef Medline

Fleming MS, Vysochan A, Paixão S, Niu J, Klein R, Savitt JM, Luo W (2015) Cis and trans RET signaling control the survival and central projection growth of rapidly adapting mechanoreceptors. Elife 4:e06828. CrossRef Medline

González-Martínez T, Germana A, Catania S, Cobo T, Ochoa-Erena FJ, de Carlos F, Díaz-Esnal B, Vega JA (2007) Postnatal developmental changes in the expression of ErbB receptors in murine Pacinian corpuscles. Neurosci Lett 420:90-95. CrossRef Medline

Griffin JW, Thompson WJ (2008) Biology and pathology of nonmyelinating Schwann cells. Glia 56:1518-1531. CrossRef Medline

Hippenmeyer S, Shneider NA, Birchmeier C, Burden SJ, Jessell TM, Arber S (2002) A role for neuregulin1 signaling in muscle spindle differentiation. Neuron 36:1035-1049. CrossRef Medline

Hippenmeyer S, Vrieseling E, Sigrist M, Portmann T, Laengle C, Ladle DR, Arber S (2005) A developmental switch in the response of DRG neurons to ETS transcription factor signaling. PLoS Biol 3:e159. CrossRef Medline

Honma Y, Kawano M, Kohsaka S, Ogawa M (2010) Axonal projections of mechanoreceptive dorsal root ganglion neurons depend on Ret. Development 137:2319-2328. CrossRef Medline

Hu X, Hicks CW, He W, Wong P, Macklin WB, Trapp BD, Yan R (2006) Bacel modulates myelination in the central and peripheral nervous system. Nat Neurosci 9:1520-1525. CrossRef Medline

Jaegle M, Ghazvini M, Mandemakers W, Piirsoo M, Driegen S, Levavasseur F, Raghoenath S, Grosveld F, Meijer D (2003) The POU proteins Brn-2 and Oct-6 share important functions in Schwann cell development. Genes Dev 17:1380-1391. CrossRef Medline

Jessen KR, Mirsky R, Lloyd AC (2015) Schwann cells: development and role in nerve repair. Cold Spring Harb Perspect Biol 7:a020487. CrossRef Medline

Klein R, Silos-Santiago I, Smeyne RJ, Lira SA, Brambilla R, Bryant S, Zhang L, Snider WD, Barbacid M (1994) Disruption of the neurotrophin-3 receptor gene trkC eliminates la muscle afferents and results in abnormal movements. Nature 368:249-251. CrossRef Medline

Knudson CM, Tung KS, Tourtellotte WG, Brown GA, Korsmeyer SJ (1995) Bax-deficient mice with lymphoid hyperplasia and male germ cell death. Science 270:96-99. CrossRef Medline

Kopp DM, Trachtenberg JT, Thompson WJ (1997) Glial growth factor rescues Schwann cells of mechanoreceptors from denervation-induced apoptosis. J Neurosci 17:6697-6706. Medline

Kucera J, Cooney W, Que A, Szeder V, Stancz-Szeder H, Walro J (2002)
Formation of supernumerary muscle spindles at the expense of Golgi tendon organs in ER81-deficient mice. Dev Dyn 223:389-401. CrossRef Medline

Loewenstein WR, Skalak R (1966) Mechanical transmission in a Pacinian corpuscle: an analysis and a theory. J Physiol 182:346-378. CrossRef Medline

Luo W, Wickramasinghe SR, Savitt JM, Griffin JW, Dawson TM, Ginty DD (2007) A hierarchical NGF signaling cascade controls Ret-dependent and Ret-independent events during development of nonpeptidergic DRG neurons. Neuron 54:739-754. CrossRef Medline

Luo W, Enomoto H, Rice FL, Milbrandt J, Ginty DD (2009) Molecular identification of rapidly adapting mechanoreceptors and their developmental dependence on ret signaling. Neuron 64:841-856. CrossRef Medline

Madisen L, Zwingman TA, Sunkin SM, Oh SW, Zariwala HA, Gu H, Ng LL, Palmiter RD, Hawrylycz MJ, Jones AR, Lein ES, Zeng H (2010) A robust and high-throughput Cre reporting and characterization system for the whole mouse brain. Nat Neurosci 13:133-140. CrossRef Medline

Mei L, Nave KA (2014) Neuregulin-ERBB signaling in the nervous system and neuropsychiatric diseases. Neuron 83:27-49. CrossRef Medline

Michailov GV, Sereda MW, Brinkmann BG, Fischer TM, Haug B, Birchmeier C, Role L, Lai C, Schwab MH, Nave KA (2004) Axonal neuregulin-1 regulates myelin sheath thickness. Science 304:700-703. CrossRef Medline

Monk KR, Feltri ML, Taveggia C (2015) New insights on Schwann cell development. Glia 63:1376-1393. CrossRef Medline

Nave KA, Salzer JL (2006) Axonal regulation of myelination by neuregulin 1. Curr Opin Neurobiol 16:492-500. CrossRef Medline

Newbern J, Birchmeier C (2010) Nrg1/ErbB signaling networks in Schwann cell development and myelination. Semin Cell Dev Biol 21:922-928. CrossRef Medline

Patel TD, Jackman A, Rice FL, Kucera J, Snider WD (2000) Development of sensory neurons in the absence of NGF/TrkA signaling in vivo. Neuron 25:345-357. CrossRef Medline

Patel TD, Kramer I, Kucera J, Niederkofler V, Jessell TM, Arber S, Snider WD (2003) Peripheral NT3 signaling is required for ETS protein expression and central patterning of proprioceptive sensory afferents. Neuron 38 : 403-416. CrossRef Medline

Pease DC, Quilliam TA (1957) Electron microscopy of the pacinian corpuscle. J Biophys Biochem Cytol 3:331-342. CrossRef Medline

Rutlin M, Ho CY, Abraira VE, Cassidy C, Bai L, Woodbury CJ, Ginty DD (2014) The cellular and molecular basis of direction selectivity of AdeltaLTMRs. Cell 159:1640-1651. CrossRef Medline

Salzer JL (2015) Schwann cell myelination. Cold Spring Harb Perspect Biol 7:a020529. CrossRef Medline

Savonenko AV, Melnikova T, Laird FM, Stewart KA, Price DL, Wong PC (2008) Alteration of BACE1-dependent NRG1/ErbB4 signaling and schizophrenia-like phenotypes in BACE1-null mice. Proc Natl Acad Sci U S A 105:5585-5590. CrossRef Medline

Sedý J, Szeder V, Walro JM, Ren ZG, Nanka O, Tessarollo L, Sieber-Blum M, Grim M, Kucera J (2004) Pacinian corpuscle development involves multiple Trk signaling pathways. Dev Dyn 231:551-563. CrossRef Medline

Sedý J, Tseng S, Walro JM, Grim M, Kucera J (2006) ETS transcription factor ER81 is required for the Pacinian corpuscle development. Dev Dyn 235:1081-1089. CrossRef Medline

Srinivasan R, Jang SW, Ward RM, Sachdev S, Ezashi T, Svaren J (2007) Differential regulation of NAB corepressor genes in Schwann cells. BMC Mol Biol 8:117. CrossRef Medline

Stassart RM, Fledrich R, Velanac V, Brinkmann BG, Schwab MH, Meijer D, Sereda MW, Nave KA (2013) A role for Schwann cell-derived neuregulin-1 in remyelination. Nat Neurosci 16:48-54. CrossRef Medline

Taniguchi H, He M, Wu P, Kim S, Paik R, Sugino K, Kvitsiani D, Fu Y, Lu J, Lin Y, Miyoshi G, Shima Y, Fishell G, Nelson SB, Huang ZJ (2011) A resource of Cre driver lines for genetic targeting of GABAergic neurons in cerebral cortex. Neuron 71:995-1013. CrossRef Medline

Taveggia C (2016) Schwann cells-axon interaction in myelination. Curr Opin Neurobiol 39:24-29. CrossRef Medline

Tessarollo L, Vogel KS, Palko ME, Reid SW, Parada LF (1994) Targeted mutation in the neurotrophin-3 gene results in loss of muscle sensory neurons. Proc Natl Acad Sci U S A 91:11844-11848. CrossRef Medline 
Tronche F, Kellendonk C, Kretz O, Gass P, Anlag K, Orban PC, Bock R, Klein R, Schütz G (1999) Disruption of the glucocorticoid receptor gene in the nervous system results in reduced anxiety. Nat Genet 23:99-103. CrossRef Medline

Uesaka T, Nagashimada M, Yonemura S, Enomoto H (2008) Diminished Ret expression compromises neuronal survival in the colon and causes intestinal aganglionosis in mice. J Clin Invest 118:1890-1898. CrossRef Medline

Willem M, Garratt AN, Novak B, Citron M, Kaufmann S, Rittger A, DeStrooper B, Saftig P, Birchmeier C, Haass C (2006) Control of peripheral nerve myelination by the beta-secretase BACE1. Science 314: 664-666. CrossRef Medline

Wolpowitz D, Mason TB, Dietrich P, Mendelsohn M, Talmage DA, Role LW (2000) Cysteine-rich domain isoforms of the neuregulin-1 gene are re- quired for maintenance of peripheral synapses. Neuron 25:79-91. CrossRef Medline

Zelená J (1980) Rapid degeneration of developing rat Pacinian corpuscles after denervation. Brain Res 187:97-111. CrossRef Medline

Zelená J (1982) Survival of Pacinian corpuscles after denervation in adult rats. Cell Tissue Res 224:673-683. Medline

Zelená J (1984) Multiple axon terminals in reinnervated Pacinian corpuscles of adult rat. J Neurocytol 13:665-684. CrossRef Medline

Zelená J (1994) Nerves and mechanoreceptors. London: Chapman and Hall.

Zhang J, Eto K, Honmyou A, Nakao K, Kiyonari H, Abé S (2011) Neuregulins are essential for spermatogonial proliferation and meiotic initiation in neonatal mouse testis. Development 138:3159-3168. CrossRef Medline 